\title{
Gestão de Incubadora de Base Tecnológica: Estudo de Caso no Setor de Agronegócio
}

\section{Technological Incubator Management: Case Study in the Agribusiness Sector}

\author{
EDUARDO AUGUSTO DE SOUZA OLIVEIRA \\ DAVID FERREIRA LOPES SANTOS \\ STELA BASSO MONTORO \\ Universidade Estadual Paulista (Unesp)
}

\section{RESUMO}

Em função da relevância assumida pelas incubadoras de empresas no desenvolvimento social e econômico regional, apoiando as empresas nascentes e a transferência de tecnologia da universidade para a sociedade, este trabalho visa analisar o modelo de gestão proposto para a Incubadora de Empresas de Base Tecnológica InovaJab utilizando-se do estudo de caso único e da abordagem qualitativa por meio da análise de conteúdo como procedimentos metodológicos. Os resultados permitiram identificar que a incubadora foi criada para atender as características econômicas e acadêmicas da comunidade em que está inserida, apresenta um espaço físico adequado para alocar as empresas e oferece serviços e recursos como treinamentos, networking e acesso aos laboratórios. Foi possível destacar os pontos fortes e fracos da gestão da incubadora e, de forma geral, concluir que melhorias no processo de seleção, nas especificidades dos cargos, nas normas claras para a graduação e nos processos e práticas da gestão precisam ser implantados visando o seu desenvolvimento contínuo.

Palavras chave: Hélice Tríplice, Inovação, Empreendedorismo, Indicadores de Desempenho, Iramuteq

\section{Abstract}

Because of the importance assumed by business incubators in social and economic development, supporting the nascent companies and the transfer of technology from the university to so- 
ciety, this work aims to analyze the proposed management model for the InovaJab Technological Base Incubator using the single case study and the qualitative approach by content analysis as methodological procedures. The results allowed to identify that the incubator was created to attend the economic and academic characteristics of the community in which it is inserted, presents an adequate physical space to allocate companies and offers services and recourses such as training, networking and access to laboratories. It was possible to highlight the strengths and weaknesses of incubator management and, in general, to conclude that improvements in the selection process, job specificities, clear norms for graduation and management processes and practices need to be implemented in order to the continuous development. Keywords: Triple Helix, Innovation, Entrepreneurship, Performance Indicators, Iramuteq

\section{INTRODUÇÃo}

Os esforços do setor produtivo no Brasil a procura por novas formas de inovação tecnológica para atender as demandas, às mudanças socioeconômicas e melhorar a competitividade tem influenciado acadêmicos e suas atividades científicas pautados no movimento baseado no conhecimento. $\mathrm{O}$ crescimento de uma economia baseado no conhecimento por meio da interação entre a universidade, empresa e governo é o escopo da teoria da Hélice Tríplice desenvolvida por Etzkowitz, segundo a qual, os parques científicos e as incubadoras de empresas são os responsáveis pela aplicação desse modelo (TISOTT, et al., 2014).

Incubadora de empresas é um organismo criado para proporcionar aos empreendedores um espaço de uso compartilhado, capacitações técnicas, apoio financeiro e agregação de valor às pequenas e médias empresas nascentes (SANTOS e MORAES FILHO, 2014).

A literatura sugere que o nível de mortalidade das empresas nos primeiros anos é alto porque carecem de experiência em gestão e habilidade para conseguir capital (XU, 2010; RUBIN, AAS e STEAD, 2015). De acordo com dados do SEBRAE (2016), a taxa de mortalidade de empresas com até 2 anos é 23,4\%, tomando como referência as empresas brasileiras constituídas em 2012. 
A mortalidade desse tipo de empresa no Brasil é causada em grande parte por dificuldades na gestão e por falta de informações sobre o mercado, surgindo as incubadoras de empresas como mecanismos que objetivam melhorar o ambiente competitivo e garantir maior sobrevida para as empresas inovadoras (BARBOSA e HOFFMANN, 2013).

Segundo a Anprotec (2016), estudos internacionais indicam que as empresas que passam por processo de incubação aumentam a probabilidade de sobrevivência no mercado ao longo do tempo porque adquirem diferenciais competitivos por meio do processo de qualificação das incubadoras.

Rubin, Aas e Stead. (2015) em um estudo sobre incubadoras de base tecnológica na Austrália e Israel afirmam que a colaboração entre as empresas incubadas, empresas graduadas e o gestor da incubadora aumentam o conhecimento das empresas incubadas em tecnologia, mercado, fontes de financiamento e probabilidade de aumento de capital. Os estudos de Dee et al. (2011) e XU (2010), também ressaltam que o processo de incubação favorece o crescimento e fortalece a sobrevivência das pequenas empresas, que representam um vital componente do crescimento da economia e do desenvolvimento social.

As incubadoras de empresas assumem papel de destaque como agentes do desenvolvimento econômico e social ao atuarem na promoção e surgimento de empresas, apoiando o desenvolvimento e a criação de novos produtos, serviços, processos e geração de emprego e renda ao otimizar o potencial dos empreendedores locais (SANTOS e MORAES FILHO, 2014; MANTOVANI et al., 2006).

Devido ao relevante papel assumido pelas incubadoras de empresas na transferência de tecnologia e indução do desenvolvimento socioeconômico em âmbito regional e até mesmo nacional, torna-se importante estudar a gestão desse tipo de organismo.

Assim, o objetivo geral deste trabalho é analisar o modelo de gestão proposto para a Incubadora de Base Tecnológica InovaJab, sediada no câmpus da Faculdade de Ciências Agrárias e Veterinárias/Unesp, do município de Jaboticabal, Estado de São Paulo. Os objetivos específicos são: identificar na literatura modelos de gestão aplicados às incubadoras de base tecnológica; entender os processos 
de gestão de uma incubadora; propor oportunidades de melhorias ao modelo de gestão da InovaJab.

Para o alcance dos objetivos traçados é apresentado um referencial teórico que contempla os conceitos sobre incubadora de empresas de base tecnológica, gestão, efetividade e indicadores de desempenho para este tipo de incubadora. Ainda, são descritos na sequência os procedimentos metodológicos usados na pesquisa, os resultados e discussões com propostas de melhorias para a gestão, as considerações finais, referências bibliográficas e os apêndices.

Por fim, espera-se que os resultados e as propostas expostas na pesquisa tragam implicações positivas para a gestão da Incubadora de Base Tecnológica InovaJab e para o seu desenvolvimento contínuo.

\section{REFERENCIAL TEÓRICO}

Neste capítulo são abordados os conceitos das incubadoras de empresas segundo a literatura e algumas associações representativas, e se destaca a importância desse tipo de organização no desenvolvimento de tecnologia, suporte às empresas, principalmente as em fase inicial, e promoção do empreendedorismo.

\subsection{Conceitos e importância de incubadoras}

A Associação Nacional de Entidades Promotoras de Empreendimentos Inovadores (ANPROTEC, 2017) define incubadora como uma entidade que tem por objetivo oferecer suporte aos empreendedores para que eles possam desenvolver ideias inovadoras e as transformar em empreendimentos de sucesso. Engelman e Fracasso (2013) afirmam que as incubadoras devem oferecer infraestrutura, capacitação e suporte gerencial, orientando os empreendedores sobre aspectos administrativos, comerciais, financeiros e jurídicos, entre outras questões essenciais ao desenvolvimento de uma empresa.

Santos e Moraes Filho (2014) e Martelo, Claro e Vieira (2016) descrevem que uma incubadora de empresa desempenha para a sociedade o importante papel de estimular o surgimento de ações empreendedoras de caráter inovador através da criação de novos produtos, serviços e processos, contribuindo para o desenvolvimento econômico e social em âmbito local, regional e, até mesmo, global. 
As incubadoras de empresas, principalmente as de base tecnológica, se tornaram um elo importante na interação entre universidades, centros de pesquisa, empresas privadas e o poder público e podem ser vistas como parceiras para o desenvolvimento tecnológico e social ao atuarem como articuladoras desses agentes no Sistema Hélice Tríplice (ROSA, 2014).

O Sistema Hélice Tríplice é uma teoria descrita por Henry Etzkowitz em que o autor defende o desenvolvimento da inovação através da relação universidade, empresa e governo (ROSA, 2014). A Figura 1 representa o Sistema Hélice Tríplice:

Figura 1 - O Sistema Hélice Tríplice

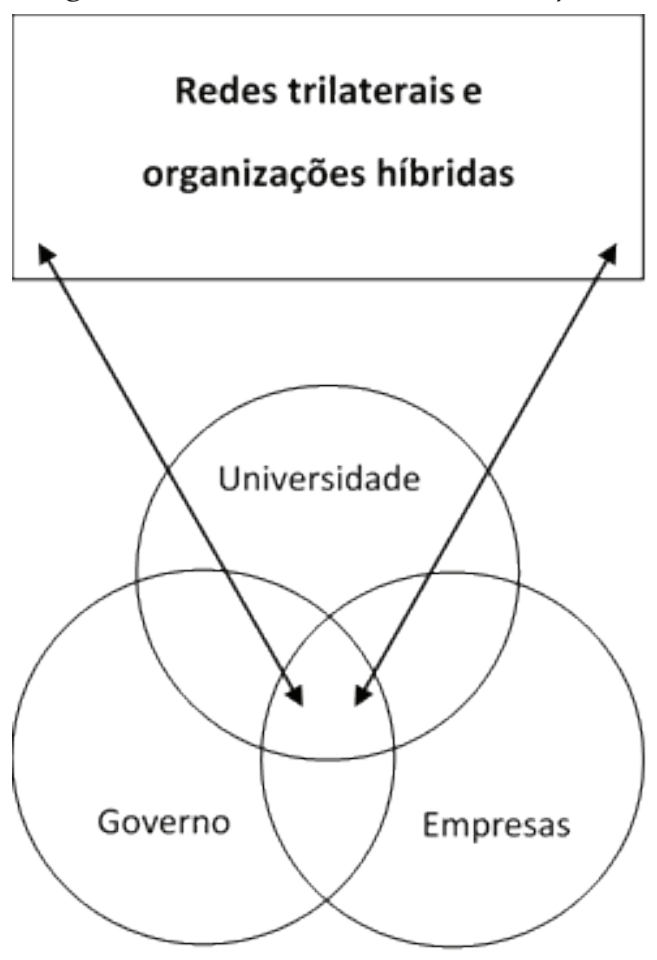

Fonte: Etzkowitz e Leydesdorff (2000, p. 111) 
Para Barbosa e Hoffmann (2013), a primeira 'pá' da hélice é representada pelo governo que assume o papel de interventor por meio de subsídios para ciência e tecnologia, incentivos fiscais e alfandegários, legislação e políticas de apoio à educação. A segunda 'pá' corresponde à universidade como responsável por criar novas fontes de conhecimento, instalar incubadoras e estabelecer novas áreas de atuação. E a terceira 'pá' da hélice se refere ao setor privado que deve atuar na geração de novos produtos e serviços e promoção da interação com os centros de tecnologia.

Rosa (2014) dizem que a geração de conhecimento tem se tornado um ponto central para a inovação e a universidade desempenha o papel de indutora das relações com as empresas e o governo através da produção de novos conhecimentos, inovação tecnológica, desenvolvimento econômico local e setorial e competitividade na micro e pequena empresa.

Xavier, Martins e Lima (2011) destacam que o relacionamento entre as incubadoras de empresas e as universidades proporcionam a ligação entre conhecimento acadêmico e aplicação empresarial, formando ambientes híbridos nos quais a dimensão científica e empresarial se encontram, capacitando o ambiente de aprendizado nas universidades e favorecendo-o para as empresas.

\subsection{Incubadora de base tecnológica}

As incubadoras são classificadas em quatro tipos segundo a Anprotec (2017): as de base tecnológica (voltadas para empresas de desenvolvimento de tecnologias), as tradicionais (auxiliam empreendimentos de setores tradicionais da economia), as mistas (abrigam tanto as empresas de base tecnológica, quanto de setores tradicionais) e as sociais (abrigam cooperativas e associações populares).

Incubadora de base tecnológica é um ambiente que hospeda empresas cujos produtos, processos ou serviços são gerados a partir de pesquisa aplicada e que resultam em tecnologia com alto valor agregado (ROSA, 2014; LIMA et al., 2014). Mansano e Pereira (2016) afirmam que a incubadora de base tecnológica deve ser reconhecida como uma ferramenta efetiva de transferência de tecnologia entre universidades e indústria, promovendo a ciência, tecnologia, inovação e facilitando a performance das empresas incubadas ao possibilitar maior contato com as redes formais e informais, eco- 
nômicas e de informação.

Mian, Lamine e Fayolle (2016) e Rubin, Aas e Stead, (2015) conceituam incubadora tecnológica como uma entidade que conecta tecnologia, know-how, talento empreendedor e capital, fornecendo para as empresas incubadas um portfólio de infraestrutura que inclui: serviços financeiros, networking, acesso a serviços profissionais, pesquisas universitárias, educação e mentoria, assim como, preparando os fundadores das empresas para participarem de eventos com grupos de potenciais investidores.

Segundo Xiao e North (2017), alguns serviços de apoio disponibilizados pelas incubadoras tecnológicas são mais propensos a influenciarem positivamente o número de empresas que se graduam, sendo os seguintes: suporte aos serviços técnicos, como o valor total investido na infraestrutura a ser disponibilizado para as empresas incubadas; suporte ao empreendedorismo, sendo o número de mentores que aconselham as empresas incubadas por meio de suas experiências anteriores; suporte financeiro, referindo-se ao suporte financeiro total disponível diretamente da incubadora para as novas empresas de base tecnológica.

Storopoli, Binder e Maccari (2013) discutem os fatores críticos do sucesso de incubadoras de base tecnológica, separando-os em três grandes categorias: relacionados ao ambiente (elementos socioculturais voltados ao empreendedorismo e governamentais de suporte aos novos empreendimentos e novas tecnologias), relacionados ao incubado (elementos que revelam o nível de educação e experiência do gestor e de traços e aspectos empreendedores pessoais) e relacionados à incubadora (serviços e suporte providos para as empresas incubadas, infraestrutura da incubadora, relacionamento e networking social, cooperação com universidades e outros centros de pesquisa, gestão da incubadora e sua estrutura organizacional).

Em um estudo do MCTI (2015) sobre o impacto da inovação no setor de tecnologia da informação por meio dos parques e incubadoras de tecnologia nas cidades, e suas respectivas regiões, de São Leopoldo/RS, Florianópolis/SC, Campinas/SP, Porto Alegre/RS, Recife/PE, Curitiba/PR e Salvador/BA durante o período de 1994 a 2013, verifica-se a evolução do número de empregos, de empresas, da representatividade dos empregos e empresas de tecnologia da informação e do índice de especialização (concentração de empregos do setor de tecnologia da informação desses municípios em relação ao Brasil). Assim, o estudo aponta para uma forte evidência de que 
os parques e as incubadoras de tecnologia contribuem fortemente para o desenvolvimento das regiões em questão. Dessa forma, torna-se importante observar se as incubadoras de base tecnológica estão cumprindo com o seu papel.

\subsection{Gestão e efetividade das incubadoras}

Santos e Moraes Filho (2014) realizaram uma pesquisa de estudo de caso múltiplo envolvendo cinco empresas em funcionamento e quatro empresas descontinuadas na Incubadora de Empresas de Base Tecnológica da Universidade Federal Rural de Pernambuco (INCUBATEC RURAL) com o intuito de analisar os projetos em andamento e investigar os projetos descontinuados. Salienta informar que foram identificados quatorze projetos de empresas nascentes no total (seis em funcionamento e oito descontinuadas), mas somente nove aceitaram participar do estudo. Ainda, este estudo entende que o termo sustentabilidade dos negócios utilizado pelos autores no artigo possa ser melhor interpretado como estratégias dos negócios. Os resultados encontrados estão transcritos no Quadro 1:

\begin{tabular}{|l|l|}
\hline Indicadores & Fatores \\
\hline $\begin{array}{l}\text { Fatores facilitadores ao } \\
\text { desenvolvimento do } \\
\text { negócio }\end{array}$ & $\begin{array}{l}\text { - Consultorias recebidas } \\
\text { - Vinculação à universidade } \\
\text { - Participação em eventos, feiras e rodadas de negócio } \\
\text { - Acesso ànformação privilegiada (técnica e de mercado) } \\
\text { - Possibilidade de realização de convênios } \\
\text { - Consolidação de parcerias }\end{array}$ \\
\hline $\begin{array}{l}\text { Fatores limitantes ao de- } \\
\text { senvolvimento do negócio }\end{array}$ & $\begin{array}{l}\text { - Tempo de dedicação para o desenvolvimento do negócio } \\
\text { por parte do empreendedor } \\
\text { - Falta de recursos financeiros } \\
\text { - Dificuldades de acesso à linha de crédito } \\
\text { - Pouco apoio da universidade }\end{array}$ \\
\hline $\begin{array}{l}\text { Sustentabilidade dos } \\
\text { negócios }\end{array}$ & $\begin{array}{l}\text { - Dificuldade em alinhar as ações da empresa com o merca- } \\
\text { do }\end{array}$ \\
\hline $\begin{array}{l}\text { Dificuldades durante o de- } \\
\text { senvolvimento do negócio }\end{array}$ & $\begin{array}{l}\text { - Criação do produto e sua inserção no mercado } \\
\text { - Busca por parcerias } \\
\text { - Falta de recursos financeiros } \\
\text { - Tempo de espera para as vendas e obtenção de recursos } \\
\text { - Tempo de dedicação para o desenvolvimento do negócio } \\
\text { por parte do empreendedor }\end{array}$ \\
\hline
\end{tabular}

Quadro 1 - Resultados do estudo de caso na INCUBATEC RURAL

Fonte: Elaborado pelo autor a partir da pesquisa de Santos e Moraes Filho (2014)

Os autores também afirmam no estudo que os empreendedores esperam por uma maior contribuição da incubadora no que diz 
respeito a criação de mecanismos de interação e integração com o meio externo para que as pessoas com vasta experiência no mercado possam transmitir seus conhecimentos para os novos empreendedores (SANTOS e MORAES FILHO, 2014). Além disso, as equipes das empresas incubadas desejam maior envolvimento dos professores e pesquisadores da universidade que encontram-se vinculada à incubadora, assim como, a utilização de mais espaços de ensino e pesquisa (SANTOS e MORAES FILHO, 2014).

Santos e Moraes Filho (2014) apresentam seis orientações para que os projetos de empresas nascentes não sofram descontinuidades: incubadora deve estar mais presente e atenta às necessidades da equipe e nuances de cada projeto de empresas; busca por mais informações; maior atenção à obtenção de recursos financeiros; conhecer melhor o negócio e o mercado a ele relacionado; uso máximo do apoio e recursos disponibilizados pela incubadora; e aproveitamento da experiência e do aprendizado adquirido.

Em um estudo de caso no Centro Incubador de Empresas de Sergipe (CISE), vinculado à Universidade Federal de Sergipe, Costa, França e Teixiera (2010) analisaram o apoio gerencial oferecido pela incubadora aos empreendimentos de base tecnológica em fase de incubação. As fontes de evidências utilizadas foram entrevistas pessoais (com o gestor da incubadora, com um empreendedor incubado há um ano e três meses e outro incubado há apenas três meses) e análise de documentos da incubadora CISE (COSTA, FRANÇA e TEIXIERA, 2010). Os resultados encontrados estão descritos no Quadro 2:

\begin{tabular}{|l|l|}
\hline Resultados & Motivos \\
\hline $\begin{array}{l}\text { Dificuldades no programa de } \\
\text { incubação }\end{array}$ & $\begin{array}{l}\text { - Escassez de recursos financeiros } \\
\text { - Formação dos empreendedores em áreas específicas e } \\
\text { pouco relacionadas a gestão }\end{array}$ \\
$\begin{array}{l}\text { - Pouca experiência em processo gerencial pelas equi- } \\
\text { pes das incubadas }\end{array}$ \\
\hline $\begin{array}{l}\text { Apoio gerencial ineficaz ofere- } \\
\text { cido pelo CISE }\end{array}$ & $\begin{array}{l}\text { - Concentrado em treinamentos e cursos de capacitação } \\
\text { em detrimento de assegurar diretamente os serviços de } \\
\text { consultoria e assessoria } \\
\text { - Busca por consultoria externa }\end{array}$ \\
\hline $\begin{array}{l}\text { Acompanhamento ineficaz das } \\
\text { incubadas }\end{array}$ & $\begin{array}{l}\text { - Equipe da incubadora é reduzida } \\
\text {-Ausência de relacionamento contínuo }\end{array}$ \\
\hline Ambiente físico adequado & $\begin{array}{l}\text {-Internet, fax, telefone, sala de reuniões, banheiros, } \\
\text { estacionamento, vigilância, limpeza, energia elétrica, } \\
\text { água, biblioteca e lanchonete }\end{array}$ \\
\hline
\end{tabular}

Quadro 2 - Resultados do estudo de caso no CISE

Fonte: Elaborado pelo autor a partir da pesquisa de Costa, França e Teixiera (2010) 
Com base nos resultados, observa-se que a incubadora CISE cumpre com o seu papel no que se refere à estrutura física, mas, por outro lado, atende de forma parcial ou é ineficaz quanto a disponibilização de assessoria/consultoria, relacionamento com os incubados e gestão da incubadora (COSTA, FRANÇA e TEIXIERA, 2010).

Azih e Inanga (2014) realizaram um estudo para verificar a eficácia no desempenho das empresas graduadas pelo Lagos Technology Incubation Centre (TIC) na Nigéria durante o período de 1997 a 2011. Os serviços de apoio considerados críticos para o sucesso do desenvolvimento das empresas no centro de incubação tecnológica foram: programa de transferência de tecnologia, simetria da informação, networking e mentoria, espaço físico e outras instalações, monitoramento e relatórios, propaganda e promoção, colaboração e benchmarking, e obtenção de fundos para investimento (AZIH e INANGA, 2014).

Os resultados do estudo indicam que dentre os oito fatores analisados, apenas simetria de informação é considerado eficaz enquanto os outros sete são considerados ineficazes (AZIH e INANGA, 2014). Por meio do Quadro 3, com base no artigo de Azih e Inanga (2014), observa-se a eficácia no desempenho e descrevem-se as causas do resultado para cada fator:

Acrescentam ainda Azih e Inanga (2014) que, apesar de alguns serviços de apoio estarem sendo executados, o problema está voltado na implementação desses serviços pelo centro de incubação tecnológica para as empresas incubadas.

Barbosa e Hoffmann (2013) realizaram um estudo de caso na Incubadora de Base Tecnológica do Centro de Apoio ao Desenvolvimento Tecnológico da Universidade de Brasília (CDT/UnB) com o objetivo de avaliar as formas de apoio como atrativo para o ingresso no processo de incubação e para consolidação das empresas.

Os resultados em termos de serviços ofertados indicam que a Incubadora de Base Tecnológica do CDT/UnB apresenta os serviços de infraestrutura física, administrativa (espaços compartilhados, copa, recepção) e serviços especializados (consultorias e assessorias), assim, atendendo o que é indicado na literatura (BARBOSA e HOFFMANN, 2013). Ainda, destaca-se o acesso aos laboratórios da universidade e relacionamentos com os professores como os serviços de maior valor agregado (BARBOSA e HOFFMANN, 2013). 


\begin{tabular}{|c|c|c|}
\hline Serviços & Eficaz & Fatores \\
\hline $\begin{array}{l}\text { Transfe- } \\
\text { rência de } \\
\text { tecnologia }\end{array}$ & Não & $\begin{array}{l}\text { Baixa qualidade em recursos humanos e baixo } \\
\text { número de treinamentos para os empreendedo- } \\
\text { res e para a equipe de gestão do TIC }\end{array}$ \\
\hline $\begin{array}{l}\text { Simetria de } \\
\text { informação }\end{array}$ & Sim & $\begin{array}{l}\text { Adequado fluxo de informação, feedback ime- } \\
\text { diato e bom relacionamento entre as empresas } \\
\text { e o TIC }\end{array}$ \\
\hline $\begin{array}{l}\text { Networking } \\
\text { e mentoria }\end{array}$ & Não & $\begin{array}{l}\text { Nível negativo em aquisição de habilidades, } \\
\text { baixo nível de desenvolvimento de ideia de ne- } \\
\text { gócios, baixa qualidade no treinamento e baixo } \\
\text { aprendizado interativo }\end{array}$ \\
\hline $\begin{array}{l}\text { Espaço físico } \\
\text { e outras } \\
\text { instalações }\end{array}$ & Não & $\begin{array}{l}\text { Espaço físico e assistência em resolução de pro- } \\
\text { blemas insuficientes, fornecimento inadequado } \\
\text { de máquinas automatizadas e interrupção do } \\
\text { fornecimento de energia elétrica por alguns } \\
\text { períodos de tempo }\end{array}$ \\
\hline $\begin{array}{l}\text { Monitora- } \\
\text { mento e } \\
\text { relatórios }\end{array}$ & Não & Sem assistência \\
\hline $\begin{array}{l}\text { Propaganda } \\
\text { e promoção }\end{array}$ & Não & $\begin{array}{l}\text { Nível baixo de exposição dos produtos em fei- } \\
\text { ras e eventos, muito baixo nível do controle de } \\
\text { desempenho da propaganda, rara frequência de } \\
\text { propaganda de mídia }\end{array}$ \\
\hline $\begin{array}{l}\text { Colabora- } \\
\text { ção e ben- } \\
\text { chmarking }\end{array}$ & Não & $\begin{array}{l}\text { Indisponibilidade de sala para interação, pouca } \\
\text { participação em eventos, falta de cooperação } \\
\text { entre os empreendedores }\end{array}$ \\
\hline $\begin{array}{l}\text { Obtenção de } \\
\text { fundos para } \\
\text { investimento }\end{array}$ & Não & $\begin{array}{l}\text { Baixo prazo de financiamento, alta taxa de ju- } \\
\text { ros e insuficiente montante disponibilizado }\end{array}$ \\
\hline
\end{tabular}

Quadro 3 - Eficácia no desempenho da Lagos

Technology Incubation Centre

Fonte: Elaborado pelo autor a partir da pesquisa de Azih e Inanga (2014).

Quanto aos resultados para as expectativas dos empresários incubados e graduados no CDT/UnB, o estudo mostra que os suportes mais atrativos, em ordem decrescente, são: consultorias e assessorias, a infraestrutura da incubadora, a permissão do uso da marca CDT/UnB em materiais gráficos, a capacitação do perfil 
empresarial, o acesso à infraestrutura da universidade e acesso a outros programas do CDT/UnB (BARBOSA e HOFFMANN, 2013). A pesquisa aponta que o suporte "acesso a outros programas do CTD/UnB", justamente o que está diretamente ligado à relação universidade-empresa, apresenta menor atratividade para os empresários, podendo significar uma possível inadequação dos serviços oferecidos (BARBOSA e HOFFMANN, 2013).

Em relação aos fatores de impacto de maior importância na consolidação das empresas graduadas e incubadas, foi feita uma análise das respostas levando em consideração as empresas com menor faturamento (até R\$ 5.000,00 mensal). É possível perceber que os suportes considerados mais relevantes para as empresas com menor faturamento estão ligados à infraestrutura e capacitação, parecendo natural que estas empresas realmente necessitem mais de infraestrutura (BARBOSA e HOFFMANN, 2013). Já as empresas com maior faturamento (acima de $\mathrm{R} \$ 10.000,00$ mensal) parecem utilizar mais os apoios que são mais próprios de uma incubadora de base tecnológica, ou seja, apropriam-se de serviços que podem agregar valor ao seu produto tecnológico (BARBOSA e HOFFMANN, 2013).

Dvouletý et al. (2018) realizaram um estudo na República Tcheca em que compararam o desempenho de 205 empresas que receberam suporte de incubadoras com 3.609 empresas que não receberam suporte de incubadoras, todas apresentando fundação após o ano 2003. Ressalta-se que as incubadoras selecionadas para a pesquisa referem-se as que recebem suporte público através de fundos da União Europeia, programas ministeriais ou dos governos regionais (DVOULETý et al., 2018).

Quanto aos resultados, o estudo empírico mostra significantes valores mais baixos dos seis indicadores de performance para as empresas incubadas em relação as não incubadas (DVOULETý et al., 2018). O valor mais baixo das vendas pelas empresas incubadas em relação as não incubadas explicam-se pelo fato de incubadoras normalmente atraírem empresas que investem no desenvolvimento de novas tecnologias dispendiosas e que conduzem para baixas receitas inicialmente, esperando-se reverter o panorama no longo período (DVOULETý et al., 2018). 
No estudo, verifica-se baixo valor agregado pelas empresas incubadas e, como este indicador reflete os processos internos, organização do negócio e produtividade, obtém-se menor competitividade e participação de mercado em relação as não incubadas (DVOULETý et al., 2018). Ainda, o baixo valor relativo de ativos comparados com as empresas não incubadas significa menor tamanho da empresa e, também, menores gastos com pessoal, indicando menores números de empregos e a alta prevalência de empregos mal pagos (DVOULETý et al., 2018).

As potenciais razões para estes resultados emergem pelo fato das incubadoras tchecas hospedarem significantes proporções de empresas velhas, maduras e grandes juntamente com as novas e inovadoras start-ups (DVOULETý et al., 2018). Localizam-se dentro das incubadoras algumas organizações não orientadas para o crescimento, como instituições públicas, sindicatos e associações que colaboram para diminuir as ambições de crescimento, motivação e esforço das equipes de empreendedores (DVOULETý et al., 2018).

Dvouletý et al. (2018) acrescentam que muitas incubadoras tchecas, principalmente as localizadas longe dos principais centros econômicos, esforçam-se para atrair um número suficiente de start-ups de alta tecnologia. No entanto, como precisam provar a sustentabilidade para seus financiadores, aceitam até mesmo empresas estabilizadas e que não tem ideias escaláveis, pois estas não são arriscadas e fornecem uma renda estável a partir do aluguel (DVOULETý et al., 2018). Além disso, a pesquisa mostra que a maioria das incubadoras não possuem informações a respeito das empresas incubadas e não rastreiam os registros de negócios durante e após o período de incubação (DVOULETý et al., 2018).

M'Chirgui (2012) apresenta um artigo em que investiga e avalia o desempenho das incubadoras de empresas na França, no período de 1999 a 2009, com base em dados originais coletados de um programa nacional criado no ano de 1999. Os resultados indicam que, após 10 anos da implantação do projeto, as incubadoras de empresas na França normalmente evoluem sem muita dificuldade e estão bem alocadas no sistema regional de inovação (M'CHIRGUI, 2012).

No entanto, as incubadoras de empresas podem precisar aumentar ainda mais o profissionalismo das principais atividades 
que apresentam alguns limites como seleção, suporte ao negócio, networking e graduação (M'CHIRGUI, 2012). A principal constatação sobre esses limites pode estar relacionada ao papel dos gestores das incubadoras no desenvolvimento dos negócios, visto que alguns limites, particularmente sobre networking e políticas de graduação, são destacados (M'CHIRGUI, 2012).

A falta de acesso a estruturas de financiamento complementares é indicada no estudo, assim como, mediação é relativamente inexistente dentro de alguns tipos de suporte como em estruturas comuns de pesquisa e desenvolvimento, clusters competitivos e em escritórios de transferência de tecnologia (M'CHIRGUI, 2012). Ainda, os treinamentos oferecidos para os incubados são um pouco ineficazes, provavelmente afetando o gerenciamento de projetos em penetração de mercado, vendas e recrutamento ineficaz de capital humano pelas incubadoras (M'CHIRGUI, 2012). Assim, uma consequência percebida é a baixa criação de vagas de emprego pelas incubadoras (M'CHIRGUI, 2012).

As recomendações do estudo se sustentam em recrutamento, pelas incubadoras, de desenvolvedores de negócios habilidosos no processo de empreendedorismo, com experiência e diferentes formações acadêmicas, possibilitando o aumento de networking e acesso a serviços cruciais como financiamento por meio da interação com investidores-anjos, capital de risco e assim por diante (M'CHIRGUI, 2012). Além disso, é necessário manter as parecerias com as autoridades locais para que seja possível consolidar diferentes serviços de apoio a inovação, a fim de permitir a identificação precoce de projetos e pesquisadores e estimular a criação de empresas inovadoras (M'CHIRGUI, 2012).

Alon e Godinho (2016) estudam em seu artigo a efetividade que as incubadoras de empresas têm tido na região Nordeste do Brasil na disponibilização de suporte às empresas incubadas. A pesquisa apresenta dados de 35 incubadoras de empresas (em um total de 36) e 93 empresas incubadas (em um total de 320), além de 14 entrevistas para avaliar o processo de incubação na região Nordeste (ALON e GODINHO, 2016).

Quanto aos resultados encontrados, o estudo descreve que a proibição imposta às universidades públicas em gerar lucro pelas 
suas atividades comerciais, assim como, a proibição aos professores de ganharem um salário para posições de gestão em seus empreendimentos (embora sejam incentivados a se envolverem em pesquisa de empresas spin-offs), inibe a profissionalização que é essencial para liderar uma empresa tecnológica, particularmente por esse tipo de organização poder levar alguns anos para gerar lucro (ALON e GODINHO, 2016).

Observa-se também que a ausência de dedicação em tempo integral dos gestores às incubadoras e às empresas incubadas resulta na baixa proatividade e baixo nível de suporte e mediação oferecido pelas incubadoras, tornando-se difícil para as empresas incubadas superarem suas dificuldades (ALON e GODINHO, 2016).

Nota-se que os problemas que as incubadoras de empresas enfrentam na região Nordeste do Brasil não são simplesmente a respeito de imperfeições na lei ou deficiências em gestão, mas também devido a terríveis problemas estruturais e outras influências históricas que levam a uma baixa qualidade do empreendedorismo (ALON e GODINHO, 2016).

Objetivando soluções, Alon e Godinho (2016) apontam que é necessário profissionalizar a equipe de gestão das incubadoras para garantir maiores responsabilidades e autonomia financeira. Além disso, recomendam que as incubadoras devem aumentar a quantidade de serviços especializados compartilhados, encontrar adequados meios de financiamentos para as empresas incubadas e promover mediação e networking (ALON e GODINHO, 2016). Ainda, que as políticas públicas devem conter normas claras para os períodos de seleção, saída e graduação e que os fundos públicos de investimentos direcionados às incubadoras e as empresas incubadas precisam ser monitorados e avaliados constantemente (ALON e GODINHO, 2016).

Com base nos estudos de caso observados neste tópico, apresenta-se no Quadro 4 as principais ações que as incubadoras devem propor para aumentarem sua efetividade. 


\begin{tabular}{|l|}
\hline Ações para aumentar a efetividade \\
\hline $\begin{array}{l}\text { 1. Consultorias, assessorias e treinamentos específicos às necessidades } \\
\text { de cada empresa }\end{array}$ \\
\hline $\begin{array}{l}\text { 2. Vínculo profundo com a universidade: maior relacionamento com } \\
\text { os professores e pesquisadores e mais acesso aos espaços de ensino e } \\
\text { pesquisa }\end{array}$ \\
\hline 3. Participação em rodadas de negócios, eventos e feiras \\
\hline 4. Maior disponibilidade de recursos financeiros \\
\hline $\begin{array}{l}\text { 5. Interação e integração com pessoas de maior experiência de mercado } \\
\text { (benchmarking) }\end{array}$ \\
\hline 6. Infraestrutura adequada \\
\hline 7. Simetria de informação: relacionamento contínuo e monitoramento \\
\hline $\begin{array}{l}\text { 8. Não hospedar empresas já estabilizadas, associações, sindicatos e } \\
\text { instituições públicas }\end{array}$ \\
\hline 9. Políticas e normas claras de seleção e graduação das empresas \\
\hline 10. Parcerias com as diversas autoridades locais \\
\hline 11. Profissionalização das equipes de gestores das incubadoras \\
\hline 12. Avaliação e monitoramento dos fundos públicos específicos \\
\hline
\end{tabular}

Quadro 4 - Ações que as incubadoras devem ter para aumentarem sua efetividade

Fonte: Elaborado pelo autor a partir dos estudos de caso observados

\subsection{Modelos de gestão de incubadoras}

Os modelos de gestão baseiam-se em três pilares básicos: pessoas, processos e tecnologias (MACHADO, SILVA e BIZZOTTO, 2017). Neste cenário, o modelo de gestão é fundamental para que as incubadoras de empresas possam atender às demandas de novos empreendedores em diferentes áreas de seus negócios (MACHADO, SILVA e BIZZOTTO, 2017).

Em um artigo sobre o mapeamento do modelo de gestão para incubadoras de empresas, Machado, Silva e Bizzotto (2017) argumentam que, no cenário internacional, o desenvolvimento de modelos de gestão para incubadoras de empresas tem sido desenvolvido desde 1985 e que o primeiro trabalho sobre esse tema é de 1988 . O estudo de Machado, Silva e Bizzotto (2017) aponta a criação de cerca de dezessete (17) modelos de gestão para incubadoras de empresas até o momento, conforme mostra a Quadro 5: 


\begin{tabular}{|c|c|c|c|}
\hline Ano & Autor & Proposta do Modelo & $\begin{array}{l}\text { Tipo de } \\
\text { Modelo } \\
\end{array}$ \\
\hline 1985 & $\begin{array}{l}\text { Campbell, Ken- } \\
\text { drick \& Samuel- } \\
\text { son }\end{array}$ & $\begin{array}{l}\text { Demonstrar as principais atividades de } \\
\text { valor agregado da incubadora }\end{array}$ & Estrutura \\
\hline 1987 & Smilor & $\begin{array}{l}\text { Mostra que a incubadora de empresas é } \\
\text { um mecanismo de transformação em que } \\
\text { indústria, governo e universidade estão } \\
\text { inter-relacionados }\end{array}$ & Estrutura \\
\hline 1988 & Nijkamp & $\begin{array}{l}\text { Analisa as incubadoras e revela os compo- } \\
\text { nentes estruturais da mesma }\end{array}$ & Estrutura \\
\hline 2000 & $\begin{array}{l}\text { Carter \& Jones - } \\
\text { Evans }\end{array}$ & $\begin{array}{l}\text { Identifica os processos-chave do processo } \\
\text { de incubação }\end{array}$ & Processo \\
\hline 2000 & $\begin{array}{l}\text { Nowak \& Gran- } \\
\text { tham }\end{array}$ & $\begin{array}{l}\text { Propõe a criação de um modelo de incu- } \\
\text { bação virtual }\end{array}$ & Estrutura \\
\hline 2000 & $\begin{array}{l}\text { Booz, Allen \& } \\
\text { Hamilton }\end{array}$ & $\begin{array}{l}\text { Introduz um modelo de incubadora de } \\
\text { empresas corporativa }\end{array}$ & Processo \\
\hline 2002 & $\begin{array}{l}\text { Lazarowich \& } \\
\text { Wojciechowski }\end{array}$ & $\begin{array}{l}\text { Descreve uma "incubadora de economia } \\
\text { nova" }\end{array}$ & Estrutura \\
\hline 2002 & $\begin{array}{l}\text { Costa-David, } \\
\text { Malan, Lalkaka }\end{array}$ & $\begin{array}{l}\text { Fornece orientação aos Estados para o } \\
\text { processo de incubação }\end{array}$ & Misto \\
\hline 2003 & Gibson, Wiggins & $\begin{array}{l}\text { Introduz um modelo para incubadoras de } \\
\text { empresas tecnológicas }\end{array}$ & Estrutura \\
\hline 2004 & Sahay & $\begin{array}{l}\text { Demonstra os principais passos de cons- } \\
\text { trução de incubadora de empresas }\end{array}$ & Estrutura \\
\hline 2004 & Hachett \& Dilts & $\begin{array}{l}\text { Apresenta os principais elementos e resul- } \\
\text { tados do processo de incubação. Consi- } \\
\text { dera a incubadora como uma tecnologia } \\
\text { facilitadora, ao invés de uma tecnologia } \\
\text { crítica ou estratégica }\end{array}$ & Estrutura \\
\hline 2004 & $\begin{array}{l}\text { Hachett \& Dilts, } \\
\text { Peters }\end{array}$ & $\begin{array}{l}\text { Explica os processos-chave na construção } \\
\text { de uma incubadora }\end{array}$ & Processo \\
\hline 2008 & $\begin{array}{l}\text { Bergek, Norr- } \\
\text { man }\end{array}$ & $\begin{array}{l}\text { Desenvolve um modelo de incubadora de } \\
\text { empresas que focará em resultados, por } \\
\text { um lado, e em trabalho com incertezas do } \\
\text { outro lado }\end{array}$ & Processo \\
\hline 2009 & $\begin{array}{l}\text { InfoDev (World } \\
\text { Bank) }\end{array}$ & $\begin{array}{l}\text { Vincula o processo de incubação ao ciclo } \\
\text { de vida do negócio }\end{array}$ & Processo \\
\hline 2010 & Jones & $\begin{array}{l}\text { Apresenta uma cadeia de valor da incu- } \\
\text { bação }\end{array}$ & Processo \\
\hline 2011 & $\begin{array}{l}\text { Chandra \& C.- } \\
\text { A. Chao }\end{array}$ & $\begin{array}{l}\text { Mostra um fluxo de recursos (dinheiro e } \\
\text { tecnologia) no ecossistema de inovação }\end{array}$ & Processo \\
\hline 2012 & Metibtikar & Mapeia os processos da incubadora & Processo \\
\hline
\end{tabular}

Quadro 5 - Modelos de gestão para incubadoras de empresas no cenário internacional Fonte: Machado, Silva e Bizzotto (2017) 
No cenário nacional, a falta de qualificação dos profissionais responsáveis pela gestão das incubadoras e pelo suporte às empresas incubadas e a significativa contribuição das incubadoras para o desenvolvimento das regiões em que estão inseridas são os principais motivos da criação do modelo de gestão Cerne (Centro de Referência para Apoio a Novos Empreendimentos) no ano de 2006, uma parceria entre o Sebrae e a Anprotec (MACHADO, SILVA e BIZZOTTO, 2017; ANPROTEC, 2016).

O objetivo da plataforma Cerne é promover melhorias significativas nos resultados, tanto quantitativo como qualitativo, das incubadoras de diferentes setores de atuação através da criação de um modelo e padrão de operação a fim de aumentar a capacidade da incubadora em gerar, sistematicamente, empreendimentos inovadores bem sucedidos (GARCIA et al., 2015; ANPROTEC, 2018). Com isso, cria-se uma base de referência para que as incubadoras de diferentes áreas e tamanhos possam reduzir o nível de variabilidade na obtenção de sucesso das empresas apoiadas (GARCIA et al., 2015; ANPROTEC, 2018).

O Cerne, como um modelo de referência em gestão de incubadoras, é um modelo nacional baseado na realidade e contexto do Brasil (MACHADO, SILVA e BIZZOTTO, 2017). Este modelo Cerne de boas práticas em gestão, estratégias, processos e serviços está alinhado com o que se tem classificado como incubadora de terceira geração (MACHADO, SILVA e BIZZOTTO, 2017).

A plataforma Cerne contempla tanto os processos genéricos a serem implantados por uma incubadora de empresas quanto as práticas que devem ser executadas para que a incubadora cumpra seu papel inovador no ecossistema local (ANPROTEC, 2016). Neste sentido, o modelo é estruturado em três independentes e complementares camadas, conforme mostra a Figura 2 (ANPROTEC, 2016).

A camada empreendimento inclui os processos diretamente relacionados com a geração e o desenvolvimento dos empreendimentos, tendo como foco os sistemas que possibilitam às empresas apoiadas desenvolverem seus produtos e serviços, acessarem capital e mercado, realizarem a gestão do negócio e promoverem o desenvolvimento pessoal dos empreendedores; o foco da camada processo são os sistemas de prospecção, geração, desenvolvimento 


\section{Figura 2 - Estrutura do Modelo CERNE}

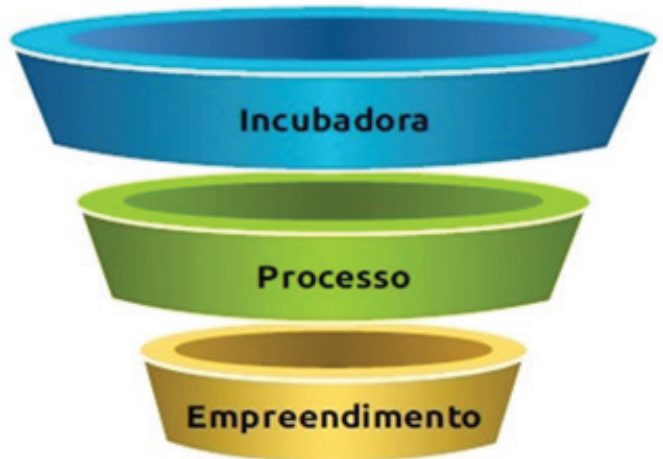

Fonte: Anprotec (2016, p. 9)

e graduação de empreendimentos inovadores, ou seja, viabilizar a transformação de ideias em negócios; na camada incubadora, o foco está na gestão da incubadora como um empreendimento e na ampliação de seus limites, com destaque para sistemas referentes a finanças, pessoas e ao relacionamento desta com o entorno (ANPROTEC, 2018).

Em função da complexidade e do número de processos-chave a serem implantados, o modelo Cerne propõe quatro níveis crescentes de maturidade como capacidade da incubadora em gerar empreendimentos inovadores de sucesso, e cada um tem seu foco específico. Dessa forma, cada nível de maturidade representa um passo da incubadora para se posicionar como um ambiente de inovação que atua profissionalmente e que gera resultados expressivos para o desenvolvimento de sua região e país (GARCIA et al., 2015).

A ideia é que as incubadoras implantem os níveis de maturidade e seus processos-chaves na sequência proposta, a fim de otimizar os recursos e facilitar o processo de implementação do modelo (GARCIA et al., 2015). Os processos-chave que as incubadoras devem implementar são mostrados no Quadro 6: 


\begin{tabular}{|l|l|}
\hline Nível de Maturidade & Processos-chave \\
\hline Cerne 1 & Atração e Prospecção \\
& Seleção \\
& Desenvolvimento dos Empreendimentos \\
& Graduação e Relacionamento com Graduadas \\
& Gerenciamento Básico \\
\hline Cerne 2 & 2.1 Ampliação de Limites \\
& 2.2 Gestão Estratégica \\
& 2.3 Avaliação da Incubadora \\
\hline Cerne 3 & 3.1 Relacionamento Institucional \\
& 3.2 Desenvolvimento em Rede \\
& 3.3 Responsabilidade Social e Ambiental \\
\hline Cerne 4 & 4.1 Melhoria Contínua \\
\hline
\end{tabular}

Quadro 6 - Nível de maturidade versus processos-chave do modelo Cerne Fonte: Elaborado pelo autor a partir do artigo de Garcia et al., 2015

A lógica em se estruturar um modelo como o Cerne consiste em se tentar reproduzir mais facilmente o sucesso de programas de incubação e, consequentemente, das empresas incubadas também (ANPROTEC, 2016). tem-se como objetivo final contribuir com a competitividade dos negócios e com o desenvolvimento local sustentável baseado na inovação (ANPROTEC, 2016).

Para Machado, Silva e Bizzotto (2017), nenhum modelo de gestão para incubadoras apresenta explicitamente a fórmula para implementação das melhores práticas no processo de incubação e poucos modelos descrevem o processo de incubação em detalhes, explicando como os serviços devem ser aplicados em casos e condições específicas de cada região onde a incubadora está localizada. Além disso, os modelos não demonstram claramente como medir a efetividade e eficácia dos processos de incubação, quais métricas de desempenho utilizar e não descrevem a importância das questões culturais para a performance da incubação (MACHADO, SILVA e BIZZOTTO, 2017).

\subsection{Indicadores de desempenho para incubadoras}

Indicadores de desempenho são índices qualitativos ou quantitativos de medição de resultados constituídos em um grupo de 
informações sobre várias áreas atuantes da empresa, o que os tornam mecanismos indispensáveis para o monitoramento estratégico de qualquer empreendimento ao fornecer embasamento às decisões gerenciais, assim como administrar a competitividade da organização (MÜLLER; LUCION; PRESRLAK; ROJO, 2017; SANTOS; QUEL; VIEIRA; ROSINI, 2019).

Ortigara et al. (2011) apresentam em seu estudo os principais aspectos que devem ser considerados em uma ferramenta de avaliação de desempenho em incubadoras: infraestrutura física, serviços administrativos, processos internos, desempenho econômico, networking, nível de inovação, geração de emprego, aprendizado e conhecimento, satisfação dos clientes, estratégia de ocupação, retenção, graduação, sociedade e stakeholders, e sustentabilidade.

Dee et al. (2011) propõem uma estrutura de avaliação de desempenho que abrange a empresa incubada e a incubadora por meio da união de vários indicadores encontrados na literatura, assinalando também para quais partes interessadas os indicadores são importantes.

É possível perceber na literatura que muitos artigos sobre avaliação de desempenho para incubadoras de empresa tratam a respeito ou trazem proposições com base na metodologia do Balanced Scorecard desenvolvido por Kaplan e Norton (1992). O Balanced Scorecard é uma ferramenta que traduz a missão e a estratégia das empresas em um conjunto abrangente e consistente de medidas de desempenho que serve de base para um sistema de medição e gestão estratégica (FERREIRA et al., 2008). O Balanced Scorecard contempla quatro perspectivas: financeira, dos clientes, dos processos internos e do aprendizado e crescimento (FERREIRA et al., 2008).

Vanderstraeten, Witteloostuijn e Matthyssens (2012) sugere uma estrutura de avaliação de desempenho para incubadoras de desenvolvimento econômico sem fins lucrativos com base no Balanced Scorecard. Souza et al. (2015) propõem um modelo de gestão e avaliação do desempenho para a Incubadora Tecnológica Natal Central com base nos mapas estratégicos e premissas do Balanced Scorecard e de acordo com as práticas-chave do modelo Cerne.

Koronta et al. (2016) propõem uma estrutura de mensuração do desempenho para o segundo nível de maturidade (desempenho da 
incubadora) do modelo Cerne alinhado ao Balanced Scorecard com o objetivo de implantar um sistema de gestão efetiva para a INTEC/TECPAR (Incubadora Tecnológica do Instituto de Tecnologia do Paraná).

O Manual de Implantação Cerne 1 e 2 destaca uma parte do documento referente ao nível Cerne 2 para descrever o processo de avaliação de uma incubadora (ANPROTEC, 2014). Conforme o manual, a incubadora deve executar três práticas-chaves: avaliação operacional, avaliação da qualidade e avaliação dos impactos (ANPROTEC, 2014).

Na avaliação operacional, a incubadora deve ter uma estrutura de avaliação dos resultados internos que utilize indicadores ou métricas que demostrem que a incubadora está operando de forma eficiente com relação, pelo menos, aos seguintes aspectos: infraestrutura (espaços de uso comum e individual e estrutura tecnológica), pessoas (envolvidas tanto com a operação quanto com a gestão estratégica), processos (atração, desenvolvimento e graduação dos empreendimentos e de marketing da incubadora) e sustentabilidade financeira (ANPROTEC, 2014). Um questionário ou um software de avaliação dos resultados operacionais da incubadora que contemple os aspectos definidos são exemplos de instrumentos que podem ser utilizados para a execução do processo (ANPROTEC, 2014).

A avaliação da qualidade envolve a implantação de um processo sistemático e documentado de ações focadas na avaliação da qualidade dos empreendimentos. Como forma de demonstrar a qualidade dos empreendimentos, a incubadora pode estabelecer uma premiação ou um selo de qualidade para os empreendimentos ou avaliar a qualidade dos produtos (ANPROTEC, 2014).

A avaliação dos impactos envolve a implantação de um processo sistemático e documentado de avaliação dos impactos da atuação da incubadora para o desenvolvimento da região, tomando como base, ao menos, um indicador (ANPROTEC, 2014). O objetivo deste processo-chave é posicionar a incubadora como instrumento efetivo de desenvolvimento, podendo-se, para este fim, analisar comparativamente o desempenho dos empreendimentos apoiados pela incubadora com os empreendimentos da região ou com base de dados secundárias como o IBGE e o IPEA (ANPROTEC, 2014).

Fonseca e Jabbour (2012) citam a existência de uma lacuna literária sobre o tema desempenho ambiental das incubadoras de 
empresas e, dessa forma, propõem uma estrutura de avaliação do desempenho ambiental das incubadoras de empresas composta por sete variáveis, com base em um estudo de caso realizado no Brasil.

Percebe-se que não há uma estrutura de avaliação de desempenho de incubadoras de empresas ou um conjunto de indicadores considerados unânimes na literatura, encontrando-se em grande parte modelos com base na metodologia Balanced Scorecard ou proposições de estruturas apoiadas em estudos de casos. Dessa forma, este trabalho pretende adicionar novos conhecimentos ao tema de modelos de avaliações de desempenho de incubadoras por meio do diagnóstico da gestão da InovaJab.

\section{MATERial e MÉtodos}

O trabalho em questão possui um caráter exploratório-descritivo que, segundo Marconi e Lakatos (2003), objetiva descrever completamente determinado fenômeno, podendo ser encontrado tanto descrições quantitativas e/ou qualitativas quanto acumulação de informações detalhadas como as obtidas por intermédio da observação participante.

Quanto à abordagem, caracteriza-se como qualitativa que, de acordo com Vieira e Rivera (2012) e Ferreira (2015), é realizada em seu ambiente natural pois os fatos têm que ser observados e analisados no contexto ao qual pertencem, através de contato direto, desempenhando o pesquisador um papel fundamental na observação, seleção, consolidação e análise dos dados gerados, podendo-se ocorrer por meio de entrevistas, fotografias, desenhos, depoimentos e outros dados que ajudem na descrição do fato.

Como modalidade de pesquisa, adotou-se o estudo de caso que objetiva ao exame detalhado de um ambiente, de um simples sujeito ou de uma situação em particular e em que o pesquisador deverá estar aberto às descobertas, atento aos novos elementos ou dimensões que podem surgir no decorrer do trabalho (GODOY, 1995). Neste trabalho empregou-se o estudo de caso único junto a InovaJab, incubadora de base tecnológica instalada na Faculdade de Ciência Agrárias e Veterinárias (FCAV), câmpus da Unesp no município de Jaboticabal, Estado de São Paulo. 
Quanto às técnicas de pesquisa, este trabalho foi elaborado como bibliográfico e por pesquisa de campo. Bibliográfico por ter sido construído a partir de levantamento de artigos científicos e outras publicações sobre os temas incubadoras, gestão e indicadores de desempenho com foco para as incubadoras do tipo tecnológica. Organizado por pesquisa de campo no levantamento das informações através de observações, coleta de documentos e aplicação de entrevistas semiestruturadas junto a InovaJab. A pesquisa de campo é utilizada com o objetivo de conseguir dados ou conhecimentos sobre um problema, ou ainda descobrir novos fenômenos ou as relações entre eles (MARCONI e LAKATOS, 2003).

A realização da pesquisa ocorreu no período de outubro de 2018 a janeiro de 2019, apresentando uma dimensão transversal. A coleta de dados deu-se por meio de visitas in loco, sítio eletrônico oficial da incubadora, análise de documentos disponibilizados pela incubadora (resumo histórico e projeto da incubadora, regulamento interno e processo de seleção das empresas) e um roteiro de entrevista semiestruturada com os três membros da Equipe Executora, responsáveis pela gestão diária da incubadora, e com um membro da Coordenação do Subprojeto InovaJab, não encontrando-se presente cotidianamente, mas integra a coordenação do subprojeto na qual a Equipe Executora necessita reportar as informações a respeito da administração da incubadora. As entrevistas foram realizadas de forma individual, conforme o Quadro 7.

\section{Quadro 7 - Identificação dos Entrevistados}

Fonte: Elaborado pelo autor

\begin{tabular}{|l|l|l|l|l|}
\hline Cargo & Vínculo & Gênero & $\begin{array}{l}\text { Ano de } \\
\text { ingresso }\end{array}$ & Tempo \\
\hline $\begin{array}{l}\text { Gestor de Novos Modelos de Ne- } \\
\text { gócios - Comunicação e presença } \\
\text { digital }\end{array}$ & Voluntário & Masculino & 2017 & 2 anos \\
\hline $\begin{array}{l}\text { Gestor de Novos Modelos de Negó- } \\
\text { cios - Relações institucionais }\end{array}$ & Voluntário & Feminino & 2017 & 2 anos \\
\hline $\begin{array}{l}\text { Gestor de Novos Modelos de Negó- } \\
\text { cios - Planejamento Estratégico }\end{array}$ & Voluntário & Masculino & 2013 & 5 anos \\
\hline $\begin{array}{l}\text { Presidente da Coordenação do } \\
\text { Subprojeto InovaJab }\end{array}$ & Coordenador & Masculino & 2016 & 3 anos \\
\hline Média & & & 3 anos \\
\hline
\end{tabular}


A entrevista semiestruturada tem seu foco no objetivo sobre o qual se confecciona o roteiro com as perguntas principais, complementadas por outras questões inerentes às circunstâncias momentâneas à entrevista e a resposta não está condicionada a uma padronização de alternativas formuladas pelo entrevistador (MANZINI, 2004). O roteiro de pesquisa aplicado encontra-se no apêndice A.

As entrevistas foram gravadas com recurso digital após anuência verbal e formal dos entrevistados em documento mantido em arquivo do grupo de pesquisa. Após a realização da entrevista, o arquivo digital foi transcrito e enviado por e-mail aos entrevistados para que os mesmos pudessem validar ou eventualmente realizar alguma alteração, inclusão ou exclusão de informações.

Neste documento são apresentados trechos das falas dos entrevistados para auxiliar no entendimento do processo de análise de conteúdo, sem a identificação dos mesmos. As informações tomadas nas entrevistas somam mais de 19.800 palavras. Para garantir maior confiabilidade às informações, a versão preliminar desse material foi enviada para os entrevistados para que eles avaliassem se o entendimento do pesquisador estaria correto.

Para análise e exploração dos dados da pesquisa selecionou-se a análise de conteúdo, que consiste em leitura aprofundada de cada uma das respostas, onde, codificando-se cada uma, obtém-se uma ideia sobre o todo, formado por textos que podem ser originados de documentos, entrevistas, reportagens, repostas abertas a questionários e dados provenientes de imagem e som (DAL-SOTO e SUZIN, 2017). A análise do modelo de gestão foi realizada seguindo o roteiro e os apontamentos dos entrevistados, procurando sinalizar as principais concordâncias e discordâncias sobre os principais itens do roteiro e relacioná-los com a literatura. Os documentos fornecidos pela InovaJab foram explorados com a finalidade de buscar elucidações sobre as ações já realizadas e os planos futuros da incubadora para auxiliar na compreensão do modelo de gestão.

Para consolidação das respostas das entrevistas semiestruturadas foi utilizado o método de Análise de Similitude e de Nuvem de Palavras por meio do software de análise textual Iramuteq (Interface de $R$ pour les Analyses Multidimensionelles de Textes et de Questionnai- 
res), que ancora-se no software $\mathrm{R}$ para realização de cálculos e na linguagem Python (DONADON, 2018).

O Iramuteq foi desenvolvido pelo francês Pierre Ratinaud e utiliza o método informatizado de análise estatística de textos na busca de assimilar a estrutura e a organização dos discursos dos sujeitos, informando as relações entre os mundos lexicais mais frequentemente expressos (DONADON, 2018). Através do Iramuteq é possível distribuir o vocabulário de forma compreensível e visualmente clara com representações gráficas oriundas das análises disponibilizadas pelo software (CAMARGO e JUSTO, 2018).

Para que se possa compreender a análise textual utilizada neste trabalho, é imprescindível a explicação de alguns conceitos importantes, segundo Camargo e Justo (2018) e Donadon (2018):

Corpus é o conjunto de textos que se pretende analisar, construído pelo pesquisador e compilado pelo Iramuteq. Neste estudo o corpus se refere ao conjunto das respostas das 4 entrevistas semiestruturadas realizadas junto aos gestores da InovaJab;

Texto é cada um dos materiais que compõem o corpus. Como há 4 indivíduos entrevistados nesta pesquisa, têm-se 4 textos pois o aglutinado das respostas de cada indivíduo representa um texto;

Segmentos de texto são partes do texto dimensionadas pelo próprio software e normalmente tem o tamanho aproximado de 3 linhas, sendo as principais unidades de análise textual deste tipo de software.

As formas de análise de dados textuais oferecidas pelo Iramuteq são: Análises Lexicográficas (estatísticas), Especificidades e Análise Fatorial de Correspondência, Classificação Hierárquica Descendente, Análise de Similitude e Nuvem de Palavras. Neste estudo, as duas últimas formas mencionadas foram selecionadas.

Análise de Similitude tem o formato inicial de um desenho de uma árvore com as respectivas ramificações, representada pela "Árvore de Semelhanças ou Similitudes (DONADON, 2018). A Análise de Similitude apresenta as relações entre as palavras e apoia-se na teoria dos grafos em que se estuda as relações de objetos de um dado conjunto, possibilitando identificar "coocorrências" entre os vocábulos e os seus resultados trazem indicações da conexidade entre as palavras que auxiliam na identificação da estrutura de 
um corpus textual (CAMARGO e JUSTO, 2018; DONADON, 2018). Permite ainda, identificar as partes comuns e as especificidades em função das variáveis descritivas identificadas na análise, sendo, assim, o resultado apresentado na forma de um grafo com várias possibilidades de visualização da ligação entre as palavras (DONADON, 2018).

Nuvem de palavras é uma forma de análise de dados textuais em que são utilizados indicadores estatísticos para agrupar e organizar as palavras em função de sua frequência (DONADON, 2018). As palavras são apresentadas em tamanhos diferentes, sendo que as maiores apresentam maior frequência e as menores apresentam frequências inferiores, possibilitando compreender quais e como as expressões no discurso dos entrevistados foram mais proeminentes (CAMARGO e JUSTO, 2018; DONADON, 2018).

Após o diagnóstico do modelo de gestão, realizou-se a interpretação e inferência de todos os dados coletados para validação dos resultados e elaboração das conclusões.

Por fim, foram propostas melhorias no modelo de gestão da incubadora Inova.Jab como meio de apoiar os gestores da incubadora e contribuir para o alcance da efetividade dos processos operacionais.

\section{RESUltados E Discussões}

Os resultados e discussões da pesquisa serão expostos em 3 subseções. Apresentação da incubadora InovaJab; contextualização das respostas das entrevistas com a literatura e consolidação da análise pelo software Iramuteq; proposição e pontos de melhoria no modelo de gestão da incubadora.

\subsection{Apresentação do caso: InovaJab}

A incubadora de empresas de base tecnológica Inova.Jab está sediada dentro da Faculdade de Ciências Agrárias e Veterinárias - FCAV/Unesp, município de Jaboticabal/SP. A faculdade oferece cinco cursos de graduação em Administração, Ciências Biológicas (licenciatura e bacharelado), Engenharia Agronômica, Medicina Veterinária e Zootecnia, dez programas de pós-graduação, com mestrado e doutorado, em doze áreas de concentração, residência médico-veterinária na área de Medicina Veterinária, além dos cursos 
profissionalizantes (Ensino Médio) de Técnico em Agropecuária e Técnico em Informática (FCAV, 2018). Além do ensino, a FCAV se destaca também pelas atividades de pesquisa e extensão universitária de qualidade, possibilitando a conquista de respeito nacional e internacional ao longo de sua existência (FCAV, 2018).

O Campus da FCAV tem estrutura física privilegiada que conta com uma fazenda de ensino, pesquisa e produção com 829 hectares de terras agricultáveis disponíveis aos professores e alunos de graduação e pós-graduação; um moderno e completo hospital veterinário voltado para a formação acadêmica, pesquisa científica e atendimento à comunidade; modernas instalações zootécnicas; inúmeros laboratórios com equipamentos de última geração; laboratórios didáticos; salas de aula; biblioteca; estação agroclimatológica; auditórios; centro de convenções; restaurante universitário, cantinas e praça de esportes (FCAV, 2018).

Na ocasião da pesquisa, a FCAV apresentava 2.776 alunos procedentes de todo o território nacional, sendo 1.614 dos cursos de graduação, 971 nos cursos de pós-graduação e 191 do Colégio Técnico (FCAV, 2018).

O Campus de Jaboticabal apresenta grande potencial científico e tecnológico instalado, humano e infraestrutura, demonstrado pelo seu significativo portfólio de pesquisas, captação de recursos na FAPESP e expressivas publicações científicas em periódicos internacionais, especialmente na área de ciências agrárias (FAPESP, 2017; FCAV, 2018). A FCAV é responsável por aproximadamente $10 \%$ de todo o conhecimento gerado na Unesp ao se considerar os 115 programas de pós-graduação distribuídos nas 33 unidades da Unesp, tem o segundo melhor indicador ( 8 artigos equivalente A1 por docente permanente por ano) ao se considerar a produção qualificada de artigos em equivalente A1 da pós-graduação brasileira e aproximadamente $40 \%$ dos docentes da FCAV são bolsistas de produtividade no CNPQ (FAPESP, 2017; FCAV, 2018).

Além disso, a FAPESP aprovou 219.421 auxílios e bolsas no período de 1996 a 2017, sendo que 20\% deste total foram captados por todos Campus Unesp e a FCAV obteve 12\% do total de aprovações dos Campus Unesp, ocupando a terceira posição e assume a primeira posição ao se considerar o número de 25 aprovações por 
docente (FAPESP, 2017; FCAV, 2018). Ainda, no período de 1992 a 2017, conseguiu 35\% das aprovações PITE (Programa de Apoio à Pesquisa em Parceria para Inovação Tecnológica), 15\% das aprovações em auxílios Políticas Públicas e 15\% das aprovações no PAPI (Programa de Apoio à Propriedade Intelectual) de todas as 33 unidades da Unesp na FAPESP (FAPESP, 2017; FCAV, 2018).

Os grupos de pesquisa vinculados aos programas de pós-graduação da FCAV captaram financiamento na FAPESP para 2.128 projetos auxílios pesquisa (21,1\% do total) e 2.920 (19,3\% do total) bolsas de mestrado, doutorado e pós-doutorado no período de 1991 a 2015 (FAPESP, 2017; FCAV, 2018).

Sustentados por esse potencial em tecnologia e inovação do campus, os programas de pós-graduação (PPGs) em ciências agrárias da faculdade e os pós-doutorandos da modalidade PNPD desses PPGs (Produção Vegetal, Ciência do Solo, Entomologia Agrícola, Microbiologia e Genética e Melhoramento Vegetal) montaram uma parceria para a criação do evento I Feira de Inovação em Ciências Agrárias realizado na Unesp de Jaboticabal em 2014 que culminou com a elaboração de uma proposta, em 2015, de desenvolvimento para instalação de um habitat inovativo na faculdade (INOVA.JAB, 2018). A iniciativa prosseguiu e em 2016 foi criada a Rede Inova.Jab com o objetivo de apoiar a criação do habitat inovativo e intensificar a discussão empreendedora na Unesp de Jaboticabal (INOVA.JAB, 2018).

A Rede Inova.Jab com o apoio dos programas de pós-graduação realizou o I Simpósio de Inovação e Internacionalização na FCAV no ano de 2017 e, no mesmo ano, após várias reuniões com representantes da AUIN (Agência Unesp de Inovação), gestores de diversas incubadoras tecnológicas, SEBRAE, Prefeitura de Jaboticabal e gestores de outras instituições tecnológicas e de pesquisa foi estruturada a incubadora que passou a levar como nome a marca Inova.Jab (INOVA.JAB, 2018).

O objetivo principal da incubadora é impulsionar a conversão do conhecimento em tecnologia e inovação no setor do agronegócio e áreas associadas (INOVA.JAB, 2018). A proposta também visa gerar vantagem competitiva científico tecnológica para o Brasil, estimular e apoiar atividades empreendedoras, fomentar projetos de parceria universidade-empresa, promover captação de recursos extra-orçamen- 
tários, viabilizar troca de experiências e transferência de know-how, e descobrir novas rotas tecnológicas (INOVA.JAB, 2018).

A incubadora de base tecnológica Inova.Jab possui três focos de atuação: agronegócio, meio-ambiente e biotecnologia, sendo as principais demandas em bioenergia, biotecnologia, automação, equipamentos e processos agrícolas, veterinários e zootécnico (INOVA. JAB, 2018). São oferecidas quatro modalidades de incubação: pré-incubado, incubado residente, incubado não residente e associado (INOVA.JAB, 2018).

Pré-incubado refere-se ao empreendedor que necessita de conceitos intermediários sobre mercado, finanças e empreendedorismo, que necessite aprender a definir estratégias e metas para amadurecer e controlar seu empreendimento (como exemplo: desenvolvimento do plano Canvas e plano de negócio), não será oferecido espaço físico e a permanência é de até 24 meses (INOVA.JAB, 2018).

Incubado residente é o empreendedor em estágio intermediário e avançado de maturidade empresarial, com plano de negócio já definido ou em fase de readequações, e que já tenha realizado testes do produto ou processo e que esteja em fase de prototipagem ou desenvolvimento de seus serviços, e permanência de até 24 meses renovável por mais 24 meses (INOVA.JAB, 2018).

Incubado não residente refere-se a empresa já constituída que atua em negócios de base tecnológicas e que não precisa de espaço físico, mas tem interesse em construir relacionamento com empresas residentes da incubadora, e podem se enquadrar nesta modalidade laboratórios ou grupos de pesquisa de outras unidades da Unesp com portfólio e expertise complementares as já oferecidas na FCAV, sendo necessário renovar o vínculo anualmente (INOVA.JAB, 2018).

Associado é a modalidade para aluno, pós-doutorado, professor, pesquisador ou empresário que deseje participar dos treinamentos e capacitações, sem interesse imediato em construir empresa ou startup (INOVA.JAB, 2018).

A Inova.Jab oferece infraestrutura física completa com espaço moderno e dinâmico para interação e troca de ideias; treinamentos, mentorias, coaching e outras atividades de formação; apoio jurídico, administrativo e mercadológico através da FUNEP (Fundação de Apoio a Pesquisa, Ensino e Extensão) que conta com certificação 
ISO 9001:2008 para gestão de projetos e ISO 31000:2009 para análise preliminar de risco; da AUIN (Agência Unesp de Inovação) na parte de propriedade intelectual, avaliação de patenteabilidade, registro de softwares e contratos de transferência de know-how; rede de contatos e parcerias para acesso a recursos e conhecimentos; captação de recursos através de capacitação em presença digital e elaboração de projetos para captação de investimentos em diferentes entidades financiadoras; networking no Setor Agro para parcerias tecnológicas com laboratórios e grupos de pesquisa interessados em apoiar as atividades de pesquisa e desenvolvimento; localização estratégica no centro do agronegócio paulista (INOVA.JAB, 2018).

É importante explicar que a FUNEP é a instituição que realiza a gestão administrativa e financeira da Incubadora InovaJab para com as empresas envolvidas no projeto, sendo uma fundação de direito privado desvinculada da faculdade, com sua sede seja dentro do campus.

Além do relacionamento com a FUNEP e com a AUIN, a Incubadora Inova.Jab também conta com o apoio dos mais de 30 laboratórios com equipamentos de ponta e os mais de 40 grupos de pesquisa nas atividades de pesquisa e desenvolvimento (P\&D) da FCAV, apoiada pela Lei da Inovação, federal (Lei no 10.973/2004) e paulista (Lei Complementar no 1.049/2008 e Decreto no 62.817/2017), e normativas da Unesp, que permitem o compartilhamento dos laboratórios, equipamentos, materiais e demais instalações das Instituições Científica, Tecnológica e de Inovação com empresas em ações voltadas à inovação tecnológica para consecução das atividades de incubação, desde que não interfira diretamente em sua atividade-fim nem com ela conflite (INOVA.JAB, 2018).

Segundo os entrevistados, a Inova.Jab tem buscado contatos com o poder executivo municipal no sentido de incentivar a inovação e o empreendedorismo localmente, com o governo estadual através da Secretaria de Desenvolvimento e Tecnologia do Estado de São Paulo e com o federal por meio da ANPROTEC, em que, inclusive, ocupa a cadeira de líderes temáticos em Agrotec. Há, também, contatos com o setor privado, em especial com a União dos Produtores de Bioenergia (UDOP), com o Banco Santander, com algumas outras associações e empresas. 
Segundo os entrevistados, a gestão administrativa da incubadora é realizada pela Equipe Executora que atualmente é composta por três membros em igual nível hierárquico mas em diferentes áreas, sendo relações institucionais, comunicação e presença digital e planejamento estratégico, e contam com o auxílio de uma estagiária do curso de Administração da FCAV. Os membros são alunos dos cursos de pós-graduação da FCAV, exercendo a atividade acadêmica paralelamente e voluntariado na gestão da incubadora, sendo que os gastos advindos nos deslocamentos das tarefas realizadas por eles são cobertos por ajudas de custo pela faculdade.

A Equipe Executora reporta suas atividades à Coordenação do Subprojeto InovaJab, composta pelo diretor da FCAV/Unesp, pelos presidentes das comissões de pesquisa, ensino e extensão da FCAV/ Unesp, diretora da FUNEP e um representante do município.

O primeiro processo seletivo da Incubadora InovaJab aconteceu em dezembro de 2017 e atualmente hospeda três empresas incubadas (NATPOL, Oikos Biotecnologia e Sabri) e duas empresas associadas (ALFA Agrotec e NATPOL) (INOVA.JAB, 2018).

\subsection{Diagnóstico do modelo de gestão}

De acordo com o referencial teórico pesquisado, as incubadoras são o elo articulador do Sistema Hélice Tríplice (universidade, empresa e governo) para o desenvolvimento tecnológico e social (ROSA, 2014).

A Inova.Jab demonstra sua atuação por meio da seleção para incubação os projetos de alunos e ex-alunos da FCAV e da Unesp em geral em um primeiro momento, auxilia na elaboração de parcerias científicas entre empresas e a FCAV e pela possibilidade das empresas incubadas formarem parcerias para utilização dos laboratórios do campus. Rosa (2014) acrescenta que a conexão entre incubadoras e universidades contribui para o fomento de programas e projetos que promovam o empreendedorismo inovador.

A InovaJab atua como interlocutora para as empresas ao buscar as melhores técnicas de gestão e produção do mercado e disponibilizá-las para as empresas. Quanto a formação e consolidação das empresas, a incubadora disponibiliza toda a parte de infraestrutura física, auxílio jurídico e de gestão, treinamentos e outros aspectos 
necessários conforme resposta de todos os entrevistados em concordância com a literatura. A interação das incubadoras com as empresas resulta na transferência de tecnologia, gerando aumento do conteúdo científico empregado no mercado, e na formação e consolidação de novas empresas tecnológicas (ROSA, 2014; ENGELMAN e FRACASSO, 2013).

O governo tem sua relação atrelada à de oferta de instrumentos, legislação e políticas de apoio para as incubadoras e as empresas para suprir as deficiências locais e regionais por meio do fomento ao empreendedorismo (BARBOSA e HOFFMANN, 2013; MANTOVANI et al., 2006). A InovaJab tem atuado perante o governo federal através da ANPROTEC, do estadual frente a Secretaria de Desenvolvimento e Tecnologia do Estado de São Paulo e mais fortemente junto ao governo municipal na busca de apoio à inovação, tecnologia e estrutura para as empresas incubadas e até mesmo após o período de incubação.

Os processos estão atendendo uma demanda interna de alunos e ex-alunos do campus ou da Unesp, uma demanda tecnológica represada. (E3).

Você pode, empresa, estabelecer um vínculo com um laboratório dentro de um departamento pela fundação, a diferença é que a Inovajab é um organismo que beneficia os interlocutores do processo. (E1).

O próximo passo é fazer um evento aqui na prefeitura para discutir com os assessores, com os secretários das diferentes pastas, leis municipais de fomento à inovação e tecnologia com o apoio da ANPROTEC, a InovaJab é associada, e a ANPROTEC vai ajudar nesse diálogo. (E3).

Com os argumentos expostos, percebe-se que a incubadora de empresas Inova.Jab está cumprindo seu papel articulador no sistema universidade-empresa-governo em conformidade com a teoria da Hélice Tríplice e que a Equipe Executora tem se esforçado para que a atuação da incubadora nas três vertentes. Nota-se que a incubadora encontra-se em um ambiente do terceiro nível dinâmico conforme explica Etzkowitz (2011), em que há a criação de redes trilaterais 
de forma que os agentes (universidade-empresa-governo) não agem mais separadamente, mas através de alianças tríades em que um agente pode assumir as funções do outro.

A Inova.Jab convive neste nível visto que a universidade cumpre com suas obrigações de ensino e, por intermédio da incubadora, também produz tecnologia em seus laboratórios e disponibiliza ao mercado através da criação ou apoio ao desenvolvimento das empresas.

A Inova.Jab, como interlocutora, e os agentes não podem ser enquadrados no quarto nível dinâmico da Hélice Tríplice, porque a universidade ainda encaminha-se para se tornar a base da economia, mas encontra barreiras internas e externas quanto a este papel de provedora do empreendedorismo e do desenvolvimento econômico e social, fatores essenciais para atingir o quarto nível conforme exposto por Etzkowitz e Klofsten (2005).

Os entrevistados concordam no geral que a universidade ainda desempenha um tímido papel de estimuladora do empreendedorismo, apesar de já observarem um avanço, e apontam a questão comportamental e cultural dos alunos, professores e instituições relacionadas e a burocracia como os principais contribuintes desse fato.

É uma questão de cultura. Tem que ser feito um trabalho de forma articulada, envolvendo várias instituições, em vários segmentos, em várias unidades administrativas para moldar a cultura, criar a cultura empreendedora. (E3).

A tramitação de documentos é um porém, porque a exigência é muito grande, seja perante a Unesp, seja perante o Estado. (E4).

Quanto à permanência das empresas no processo de incubação, pode-se dizer que a Inova.Jab atua positivamente visto que apenas uma das seis empresas abandonou o projeto por fatores e características pessoais de aderência ao empreendedorismo do gestor da empresa em questão segundo afirmações dos entrevistados.

O perfil de negócio das empresas vinculadas à Inova.Jab tem foco em segmentos do agronegócio como meio ambiente, biotecnologia e também em e-learning. As empresas incubadas e associadas 
atualmente concentram-se nas áreas de controle biológico, polímeros, consultoria agropecuária presencial e on-line e de cafés especiais. Com isso, percebe-se que o perfil de negócio das empresas incubadas e associadas atualmente é coerente com as especialidades oferecidas pela incubadora e pela sua Equipe Executora.

Sobre o perfil inovador, os entrevistados foram questionados se já havia a constatação de algum processo, produto ou serviço inovador já lançado ao mercado por alguma empresa incubada pela Inova.Jab e argumentaram que duas empresas, uma na área de controle biológico e outra na fabricação de polímero, já estão com processos mais avançados, inclusive em contato com fornecedores e investidores.

Os exemplos citados compactuam com a idealização do projeto Inova.Jab de uma incubadora do tipo tecnológica e promotora de inovações e demonstram que resultados positivos já estão sendo alcançados mesmo com pouco tempo de existência da incubadora. Em concordância, Rosa (2014), Lima et al. (2014) e Mansano e Pereira (2016) dizem que incubadora de base tecnológica acolhe empresas que geram produtos, processos ou serviços inovadores com alto valor agregado, possibilitando a transferência de tecnologia entre universidade e indústria.

Em vários momentos de todas as entrevistas é possível captar os inúmeros serviços e as condições da estrutura física ofertada às empresas e não se observa nenhum serviço ou recurso de alta relevância que não é disponibilizado pela incubadora Inova.Jab e que poderia influenciar na qualidade da incubação conforme indica a literatura segundo Rubin, Aas e Stead, 2015; Mian, Lamine e Fayolle, 2015.

São desde a infraestrutura, espaço físico, energia elétrica, internet, secretária, espaço de salas para treinamentos, mobiliários, estacionamento, serviço de segurança, limpeza. Agora, na parte de treinamentos são mentorias com empresas que já estão no mercado, empresas de ex-alunos ou empresas multinacionais que tem parceria com a universidade, apoio na parte de propriedade intelectual, possíveis patentes, registro de softwares, registro de cultivares, apoio na elaboração de projetos com possíveis riscos jurídicos, apoio na parte de presença digital, construção de site, valorização de produtos ou serviços. (E3). 
Storopoli, Binder e Maccari (2013) citam três categorias de fatores críticos de sucesso para incubadoras de base tecnológica: relacionados ao ambiente, relacionados ao incubado e relacionados à incubadora.

Quanto aos relacionados ao ambiente, a questão dos elementos socioculturais voltados ao empreendedorismo precisa ser mais explorada na FCAV e até mesmo na comunidade local conforme já fora discutido anteriormente.

Quanto aos incubados, pode-se inferir por meio das entrevistas com a Equipe Executora que eles apresentam nível educacional elevado pois são alunos de pós-graduação, ainda prezam um pouco na falta de experiência em gestão pois são empresas em ciclos iniciais e apresentam características empreendedoras por desejarem transferir os produtos de suas pesquisas para o mercado, excluindo-se a gestora da empresa que abandonou o processo de incubação.

Os fatores relacionados à incubadora são totalmente abrangidos pela Inova.Jab nos serviços e recursos ofertados às empresas incubadas como já fora mencionado no tópico sobre serviços e recursos disponibilizados por uma incubadora de base tecnológica.

Na questão da oferta de consultorias, assessorias e treinamentos específicos a cada empresa incubada, percebe-se que a Inova.Jab disponibiliza inicialmente treinamentos e capacitações mais genéricas através da própria Equipe Executora e posteriormente, como ponto de maior destaque e considerado essencial para a efetividade de uma incubadora, busca auxílios mais técnicos para cada necessidade individual das empresas.

Nós já firmamos algumas parcerias, por exemplo temos uma parceria com a Futura Business que é uma empresa de recursos humanos que já concordou em vir dar treinamento para o pessoal na parte de liderança, recursos humanos. (E2).

A respeito da utilização dos espaços de pesquisa e laboratórios da FCAV, os entrevistados deixam claro a relação necessária entre empresas, laboratório (incluindo o departamento a que está atrelado) e FUNEP, e a Inova.Jab atuando como interlocutora dessa interação, para que seja permitido o uso desses espaços e dos equipamentos. 
Além do uso dos laboratórios, as empresas incubadas e incubadas não residentes também podem se relacionar com os professores e pesquisadores a eles conectados, que promove troca de conhecimentos e informações e traz benefícios tanto para as empresas quanto para a faculdade.

Um ponto de certa preocupação nessa questão do uso dos laboratórios é o aval do departamento em permitir se relacionar com a Inova.Jab e consequentemente com as empresas incubadas visto que a comunidade da FCAV ainda apresenta uma certa resistência ao empreendedorismo e ao relacionamento da universidade com empresas. No entanto, a Lei Federal 13.243/2016 do Marco Legal e o Decreto № 62.817/2017 do Estado de São Paulo que regulamentam a interação das empresas com os espaços de pesquisa e a FUNEP como gestora do contrato a ser celebrado entre laboratório e empresas trazem credibilidade e contribuem para que o relacionamento possa ser efetivado.

A participação das empresas incubadas em rodadas de negócios, eventos e feiras é um dos fatores considerados essenciais para a efetividade das incubadoras pois conecta as empresas ao mercado (SANTOS e MORAES FILHO, 2014). Os entrevistados concordam com o tema acima, explicam sua importância e até narram um caso de uma empresa que já conseguiu despertar interesse de um investidor.

Sim, esse financiamento de possibilidade de parceria entre as incubadas e as empresas surgiram de rodadas de negócios, umas delas aconteceu em um evento de patentes promovido pela Supera Parque, nossa parceira, e era um evento com foco em patentes de biotecnologia, uma das nossas empresas tem patente e uma das empresas do mercado já se interessou. (E3).

Esse depoimento corrobora a importância da Inova.Jab em intermediar as conexões entre empresas e mercado/investidores em rodadas de negócios, eventos e feiras, demonstrando que a incubadora já está alcançando resultados mesmo com pouco tempo de existência.

Santos e Moraes Filho (2014), Costa, França e Teixiera (2010) e Azih e Inanga (2014) pontuam que as empresas incubadas precisam 
ter acesso a recursos financeiros para financiarem suas atividades. A Inova.Jab ainda não é capaz de disponibilizar financiamentos/ recursos financeiros diretamente para as empresas incubadas ainda porque nenhuma empresa gerou retorno financeiro de seu produto ou serviço visto que as atividades e as assinaturas dos contratos são recentes.

A interação e integração das empresas incubadas com pessoas de maior experiência de mercado é bem vista na Inova.Jab, inclusive a incubadora já promove ações nesse sentido através dos eventos, feiras, palestras e contato com empreendedores egressos dos campi da Unesp. O relacionamento contínuo e o monitoramento das empresas incubadas são fatores essenciais na efetividade das incubadoras conforme Costa, França e Teixiera (2010).

$\mathrm{Na}$ época da visita in loco, a InovaJab não estava utilizando ferramentas de controle devido as assinaturas dos contratos serem recentes, mas estava por implantar um software cedido pelo Supera Parque (Parque de Inovação e Tecnologia de Ribeirão Preto) para realizar o acompanhamento e monitoramento das empresas. Além da implantação do software, os entrevistados acrescentam que o monitoramento das empresas incubadas contará também com estagiários denominados insiders que auxiliarão no cumprimento das metas e tarefas.

O software de monitoramento facilitará o acompanhamento do desenvolvimento das empresas tanto pela Equipe Executora como pelos próprios proprietários e a inclusão de insiders é uma proposta muito interessante para manter o vínculo próximo, mas que precisará ser analisada se trará os resultados esperados. Ainda, é preciso que o acompanhamento seja realizado frequentemente e presencialmente também pela Equipe Executora, não somente com os insiders, para verificar se as empresas estão cumprindo os prazos e metas estabelecidos para o alcance da graduação.

Questionados se a InovaJab hospeda empresas já estabilizadas, associações, sindicatos e instituições públicas, os respondentes foram claros que no momento não hospedam, que o tipo de empresas que a incubadora busca é de base tecnológica e em fase de desenvolvimento. Porém, caso alguma empresa ou instituição queira fazer parte da rede InovaJab, ela pode participar do processo seletivo na modalidade associada ou incubado não residente. 
As quatro fases do processo de seleção empregadas pela InovaJab se apresentam teoricamente como uma forma adequada de selecionar as empresas, inclusive por se enquadrar o plano de negócios no formato do PIPE-FAPESP e, assim, a empresa já ter a oportunidade de inscrever o projeto ao final do processo.

Além do contrato e do plano de negócios, é recomendável o estabelecimento de um guia mínimo de pontos estratégicos que as empresas e empreendedores devem realizar e que contemple a aprendizagem, a ser adquirida pelos empreendedores como cursos e treinamentos de vendas, marketing, gestão e outros, os processos que as empresas precisam implantar e as etapas do desenvolvimento e inserção do produto/serviço para o mercado de forma clara, orientando o percurso para o alcance da graduação pelas empresas incubadas e auxiliando a visualização do nível de desenvolvimento em que se encontram.

A parceria com setores governamentais e privado é um dos pilares do conceito da Hélice Tríplice (universidade-empresa-governo) e fator essencial também para a efetividade de uma incubadora (ETZKOWITZ e LEYDESDORFF, 2000; M'CHIRGUI, 2012). No lado governamental, a Equipe Executora da Inova.Jab não assinou concretamente uma parceria com autoridades locais. Em nível estadual a incubadora está em processo de regularização junto a Secretaria de Desenvolvimento e Tecnologia do Estado de São Paulo e a nível federal tem parceria assinada com a ANPROTEC.

Quanto ao setor privado, a Inova.Jab apresenta uma política de busca por parceiras com entidades que englobem um grupo de empresas como a UDOC e a ABAG por atingir uma escala maior, mas claro que também preza pelo relacionamento individual.

Uma equipe gestora com perfil profissional específico na área que atua dentro da incubadora é uma das características para o alcance da sua efetividade e a ausência de dedicação em tempo integral dos gestores às incubadoras e às empresas incubadas resulta na baixa proatividade e baixo nível de suporte e mediação oferecido pelas incubadoras (ALON e GODINHO, 2016).

Percebe-se que os entrevistados não possuem um consenso sobre o tema muito pelo fato de dois deles conectarem a graduação em engenharia agronômica com o perfil agrário da incubadora, 
acreditando que esse paralelo, juntamente com os demais cursos, especializações e experiência profissional que absorveram, abrangeria todas as habilidades requeridas para os cargos que ocupam na Inova.Jab. O ideal segundo a literatura é que a Equipe Executora tenha graduação específica em áreas de gestão e nas áreas que atuam para oferecerem um serviço profissional.

Observa-se, ainda, que a Equipe Executora não tem dedicação em tempo integral à gestão da incubadora pois cursam paralelamente a pós-graduação na FCAV, empreendendo esforços na realização das duas atividades e não permitindo a implantação de foco em uma específica, o que resulta em baixo nível de suporte às empresas incubadas segundo a literatura.

A Inova.Jab não segue um modelo de gestão específico para incubadoras, mas elaborou um modelo não engessado com base em observações nos modelos de outras incubadoras e nas necessidades locais.

A Inova.Jab agiu bem ao observar vários modelos de gestão de incubadoras para retirar o máximo de informações possíveis e implantar um modelo que trouxesse resultado satisfatório. Porém, é preciso propor uma gestão que apresente os processos-chave de cada área e como as ações práticas devem ser executadas, não sendo aconselhável um modelo gerencial que tentará resolver uma situação conforme ela apareça aos gestores.

Vários modelos de gestão são propostos, mas é difícil indicar um que seja o ideal pois vários fatores devem ser levados em consideração, inclusive as caraterísticas do habitat em que a incubadora está instalada. A percepção é que a Equipe Executora agiu bem em empreender esforço na observação de vários modelos para elaborar um que é adequado com o perfil da faculdade e da região. Mas, precisa-se propor claramente no modelo de gestão os processos e as práticas para direcionar o crescimento da incubadora. Além disso, a implantação do modelo Cerne será de extrema importância para ampliar a conexão da incubadora com outros ambientes de inovação que seguem o modelo e também para o desenvolvimento contínuo do modelo ao longo do tempo.

A Inova.Jab demonstra estar encaminhando para se tornar uma incubadora de empresas de base tecnológica reconhecida, mas com a necessidade de alguns ajustes, principalmente, na parte gerencial, 
sendo difícil sua mensuração no momento pois suas atividades iniciaram há pouco tempo e uma avaliação organizacional mais completa poderá ser realizada com a implantação do software cedido pelo Supera Parque. É esperado que o software contemple indicadores de desempenho mencionados na pesquisa, não necessariamente um modelo específico, mas indicadores que auxiliem na autoavaliação e desenvolvimento contínuo da Inova.Jab.

Com a utilização do software Iramuteq, elaborou-se uma análise da conexão das palavras dos entrevistados com vistas a entender melhor o diálogo entre eles. A Figura 3 abaixo, identificada como Árvore de Semelhanças ou Árvore de Similitudes, representa a formato inicial de uma árvore em que o resultado representa a interação entre as partes envolvidas.

Figura 3 - Árvore de Semelhanças ou Árvore de Similitude

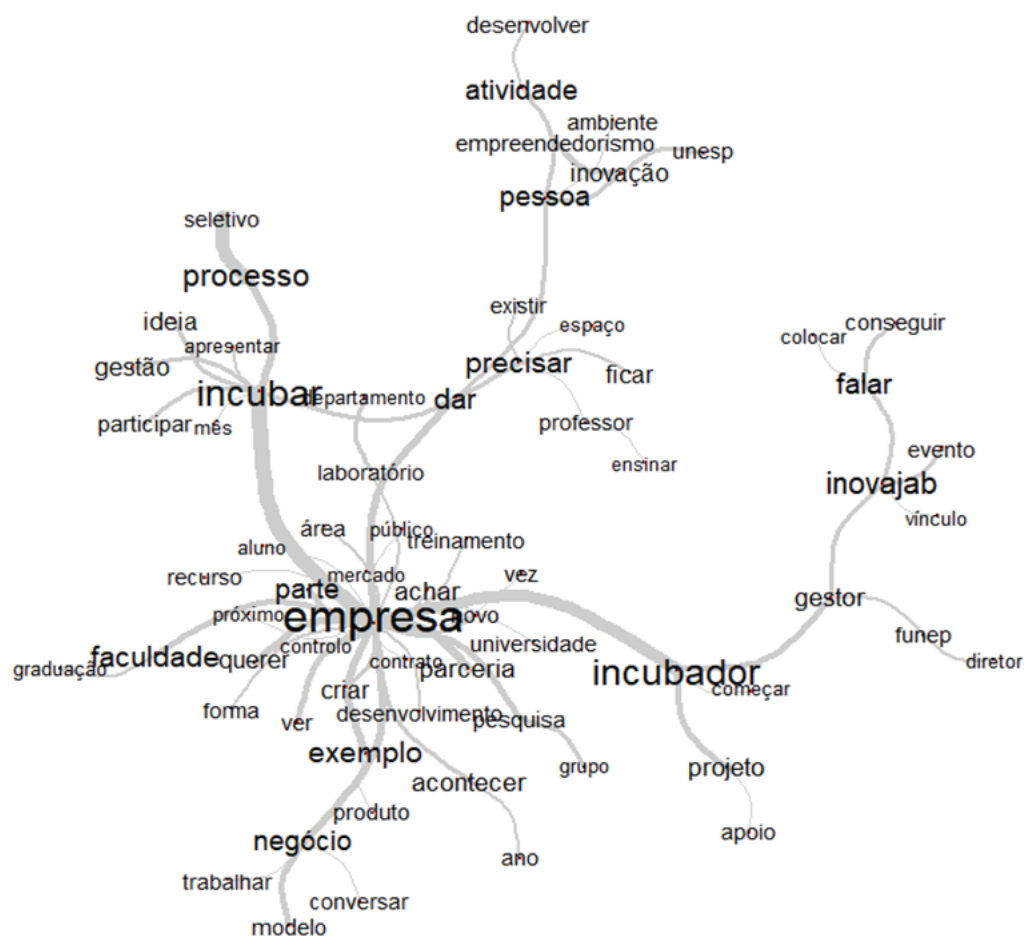

Fonte: Dados da pesquisa (2019) 
Para gerar a Figura 9, o software Iramuteq selecionou as palavras que se repetiam 15 vezes ou mais no discurso dos entrevistados, sendo a palavra "empresa" com 156 repetições a que mais ocorreu, seguida da palavra "incubadora" (emitida pelo software como "incubador" na Figura 9) com 94 repetições e da palavra "incubar" com 90 repetições.

Pode-se perceber que a palavra "empresa" apresenta o ponto central da árvore de onde saem o maior número de ramificações, com destaque para os ramos mais grossos que se conectam as palavras "incubar" e "incubadora", validando o propósito de relacionamento entre a incubadora Inova.Jab e as empresas.

As ramificações ao redor da palavra "empresa" como as palavras "universidade", "faculdade", "mercado", "treinamento", "parceria", "laboratório" e "pesquisa" indicam a conexão existente entre esses lugares no ambiente pesquisado, demonstrando que a Inova. Jab tem conhecimento do seu papel de aproximar essas entidades para gerar resultado positivo para as empresas.

Outro destaque se refere a proximidade das palavras "ambiente", "empreendedorismo", "unesp" e "inovação", comprovando o exposto nos diálogos no que diz respeito a criação de um habitat de desenvolvimento de tecnologia no campus da FCAV e em toda a comunidade da UNESP.

A partir da Figura 3, o software Iramuteq produziu a Figura 4 em cores que representa o resultado da Análise de Similitude. Na Figura 10 deve-se analisar as áreas em que os vocábulos do corpus textual compilado nas entrevistas interagem com os entrevistados em maior ou menor intensidade, sendo que o tamanho dos vértices coloridos é proporcional à frequência das palavras e as arestas indicam a força da coocorrência entre os vocábulos (DONADON, 2018).

Evidencia-se, a partir da Figura 4, que o Entrevistado 2 apresenta a melhor interação com os outros três entrevistados pois os vocábulos que mais expressam sua perspectiva da Inova.Jab também estão presentes nos discursos de todos os entrevistados. No entanto, nota-se que o Entrevistado 2 e o Entrevista 3 apresentam maior alinhamento de ideias

O entrevistado 4 demonstra uma conexão fraca dos seus vocábulos pois os pontos de intersecção com os demais participantes são restritos, o que reflete as respostas divergentes da sua entrevista em relação aos outros três entrevistados. 


\section{Figura 4 - Análise de Similitude}

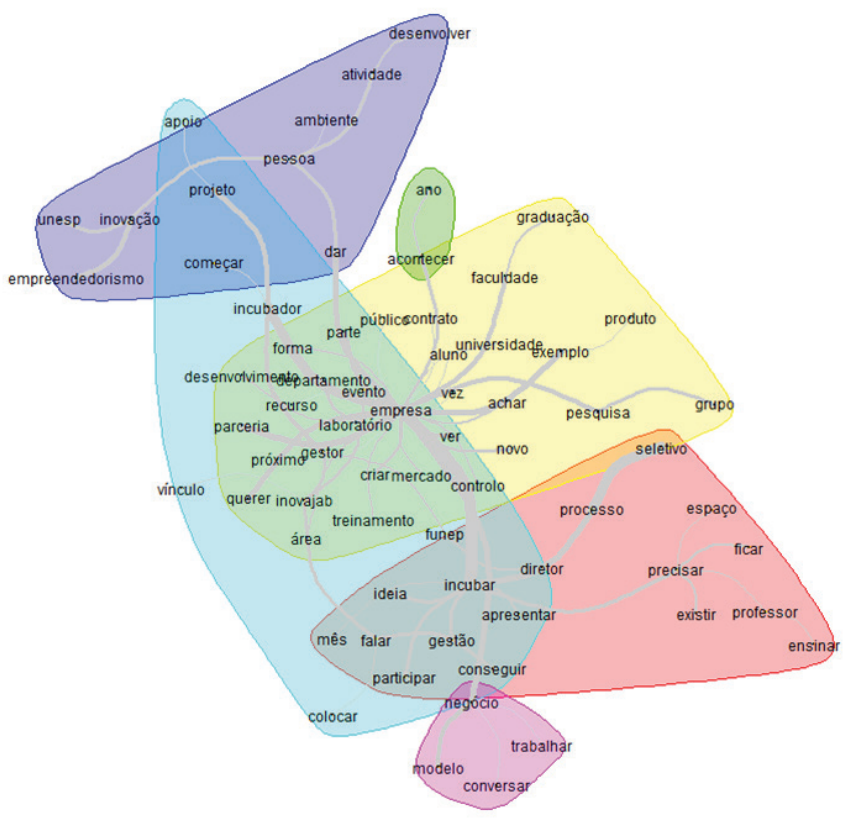

Fonte: Dados da pesquisa (2019)

Percebe-se que não há uma conexão dos vocábulos entre todos os entrevistados pois as áreas não estão se correlacionando adequadamente, apresentando-se praticamente paralelas umas às outras entre os Entrevistados 1, 3 e 4, visto que não transitam por todos os campos de cores, e somente o Entrevistado 2 correlacionando entre eles. Assim, valida-se que a comunicação entre os membros ainda imprecisa o que sinaliza para a necessidade de uma estrutura de gestão que possibilite o alinhamento de ações como o estabelecimento de reuniões de análise crítica, a criação de painéis de indicadores alinhados aos programas e projetos.

A Figura 5 representa o resultado emitido pelo Iramuteq para a análise por Nuvem de Palavras, que nada mais representa do que o agrupamento e a organização das palavras em função da frequência das mesmas. 
Figura 5 - Nuvem de Palavras

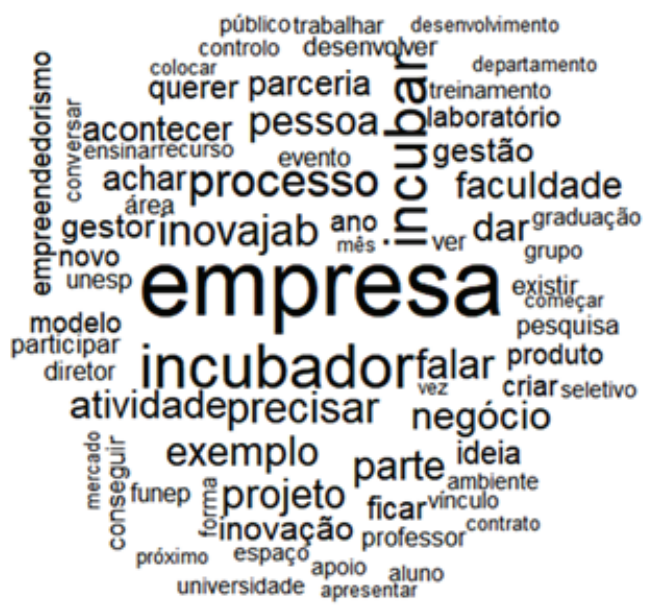

Fonte: Dados da pesquisa (2019)

As palavras destacadas em tamanhos maiores e com negrito mais acentuado representam as palavras mencionadas um maior número de vezes, demonstrando a conexão dos diálogos dos entrevistados da pesquisa.

Pela imagem acima é possível visualizar mais uma vez que as palavras "empresa", "incubadora" (apresentada novamente pelo Iramuteq como "incubador") e "incubar" são as que aparecem repetidamente mais vezes, ratificando os resultados expostos em todo o contexto da pesquisa.

Assim, é possível perceber que a análise por "Nuvem de Palavras" corrobora os resultados encontrados anteriormente na Análise de Similitude, uma vez que as duas análises mostram evidências de discursos semelhantes na pesquisa.

Os resultados por "Árvore de Semelhanças" e "Nuvem de Palavras" ajudam a ratificar os resultados encontrados a respeito da necessidade de conectividade das empresas com a faculdade e seus laboratórios, pesquisas, professores e treinamentos por meio da interlocução da incubadora Inova.Jab. Ainda comprova o objetivo de implantação de um habitat de inovação e empreendedorismo dentro do câmpus da FCAV ao indicar a conexão das palavras que remetem a esse propósito nos resultados apresentados. 


\subsection{Proposição de melhorias na gestão}

Com base nos resultados e discussões foram encontrados pontos fortes e fracos da Inova.Jab e pretendesse com este tópico propor algumas melhorias na gestão da incubadora.

\begin{tabular}{|l|l|}
\hline Pontos Fortes & Pontos de Melhoria \\
\hline $\begin{array}{l}\text { Atendimento à demanda in- } \\
\text { terna da FCAV }\end{array}$ & Estímulo à cultura empreendedora \\
\hline Desenvolvimento da região & Período do processo seletivo \\
\hline Estrutura física e serviços & $\begin{array}{l}\text { Avaliação do abandono do processo de } \\
\text { incubação }\end{array}$ \\
\hline $\begin{array}{l}\text { Networking com pessoas } \\
\text { experientes }\end{array}$ & $\begin{array}{l}\text { Frequência das reuniões entre Equipe } \\
\text { Executora e Coordenação do Subproje- } \\
\text { to InovaJab }\end{array}$ \\
\hline $\begin{array}{l}\text { Conexão com professores e } \\
\text { pesquisadores }\end{array}$ & $\begin{array}{l}\text { Verificação da influência das empresas } \\
\text { associadas }\end{array}$ \\
\hline Insiders & Guia para o alcance da graduação \\
\hline & $\begin{array}{l}\text { Especificar claramente as funções dos } \\
\text { gestores }\end{array}$ \\
\hline & $\begin{array}{l}\text { Estruturar os processos e práticas da } \\
\text { gestão }\end{array}$ \\
\hline & Análise do software a ser implantado \\
\hline
\end{tabular}

Quadro 8 - Pontos fortes e de melhorias da InovaJab

Fonte: Elaborado pelo autor a partir dos dados da pesquisa

$\mathrm{O}$ atendimento à demanda interna das pesquisas e desenvolvimento de tecnologias nos cursos de pós-graduação represadas na FCAV é visto positivamente devido aos resultados sociais e econômicos que a inserção de novas tecnologias e criação de empresas pode trazer para o desenvolvimento da região. Um dos fatores que contribuirão para essa questão é a infraestrutura adequada e a gama de serviços que a Inova.Jab oferece para as empresas que se vinculam a ela.

O networking com grupos de empresas, atingindo um grande número de pessoas qualificadas e experientes também é outro ponto de grande valia oferecido pela Inova.Jab. Ainda, no mesmo 
sentido, a conexão com os professores e pesquisadores da FCAV e a possibilidade de utilização dos laboratórios da faculdade para o desenvolvimento das pesquisas pelas empresas.

Na parte de gestão, a inclusão do insider é um fator considerado interessante e diferencial para o monitoramento e comunicação com as empresas, precisando os resultados de suas ações serem analisados futuramente para compreensão do verdadeiro retorno à incubadora e às empresas. Caso seja positivo, é um modelo que pode ser aplicado por outras incubadoras para o atendimento dos mesmos objetivos.

As citações as constantes buscas por parcerias tanto públicas como privadas, com algumas já concretizadas, por todos os entrevistados, a implantação do espaço físico da incubadora e todas as outras inúmeras ações já realizadas demonstram o empenho da Equipe Executora e da Coordenação do Subprojeto Inova.Jab na idealização deste projeto e também é considerado um fator positivo e de destaque para a incubadora, demonstrando pensamento para o contínuo desenvolvimento institucional da incubadora e alcance de melhores resultados.

A pesquisa captou que a comunidade da FCAV não tem uma cultura totalmente empreendedora e que por essa questão a Inova.Jab sente algumas restrições em suas ações. O estímulo para a mudança desse perfil precisa ser mantido por meio de eventos no campus a cargo da Inova.Jab e esforço por meio da incubadora na sensibilização dos departamentos para a inserção de matérias sobre inovação e empreendedorismo nos cursos de graduação e pós-graduação. Com os resultados positivos a serem alcançados pela Inova. Jab, os argumentos se tornarão mais concretos e a percepção das pessoas mais resistentes tenderá a mudar.

Como as assinaturas dos primeiros contratos precisaram de um período de tempo maior que o desejado por causa da mudança de direção na FUNEP, aconselha-se que o processo seletivo não ocorra coincidentemente na mesma época em que é realizada a troca de gestão da fundação.

O abandono do processo de graduação por uma empresa não é um fator bem visto para as incubadoras e como a Inova.Jab já apresenta um caso sendo uns dos motivos a não aderência ao perfil 
empreendedor pela proprietária da empresa, a inclusão de uma avaliação comportamental ou investigação do perfil dos proprietários das empresas durante o processo de seleção ajudaria a evitar nova ocorrência do mesmo tipo.

É recomendável aplicar uma pesquisa com a proprietária da empresa que abandonou o processo de incubação com o intuito de descobrir os principais motivos do abandono segundo as suas justificativas e também em ter um feedback sobre o processo de incubação oferecido e sobre a gestão da incubadora.

É difícil indicar um período de tempo para a realização de reuniões entre a Equipe Executora e a Coordenação do Subprojeto InovaJab pois vários fatores estruturais e pessoais são envolvidos, mas alerta-se que uma única reunião geral realizada dentro de 10 meses não é considerada ideal e ocasiona desconexão das informações como pode ser observado em algumas questões durante a pesquisa e também pela Análise de Similitude (Figura 10). Assim, deve-se buscar um período de tempo em comum acordo para que o acompanhamento da incubadora seja de conhecimento de todos os envolvidos.

Como a literatura sugere que empresas já estabilizadas no mercado podem influenciar negativamente as empresas em processo de incubação quando convivem em mesmo ambiente, é recomendável verificar se as empresas associadas podem estar trazendo algum prejuízo para as empresas incubas e incubadas não residentes apesar das empresas da modalidade associada apenas se beneficiarem de treinamentos e capacitações e não integrarem o espaço físico da incubadora.

Aconselha-se estruturar um guia com os pontos estratégicos para o alcance da graduação, sendo possível a orientação e o acompanhando do desenvolvimento do negócio tanto pela Equipe Executora como pelas empresas incubadas.

Sugere-se especificar as funções de cada cargo da Equipe Executora como meio de auxiliar o desenvolvimento da incubadora e oferecer um suporte adequado às necessidades gerais e individuais das empresas incubadas.

Com as informações do perfil da faculdade, da região e através dos modelos de gestão observados, é preciso propor uma gestão 
que apresente os processos-chave de cada área e como as ações práticas devem ser executadas para direcionar o desenvolvimento da incubadora.

Considerando a implantação do software cedido pelo Supera Parque posterior a visita in loco à incubadora, é indicado que seja realizada uma análise da eficácia do software para o monitoramento das empresas e na avaliação organizacional da incubadora visto que esse software é utilizado em habitat de inovação com perfil um pouco diferente do vivenciado pela InovaJab.

\section{CONSIDERAÇõeS FINAIS}

A Incubadora de Base Tecnológica Inova.Jab foi construída através de muito estudo e networking para atendar as demandas específicas da faculdade e da região em que está inserida. Percebe-se que apesar das dificuldades encontradas como certa indisposição a cultura empreendedora e falta de recursos financeiros iniciais, a Equipe Executora e a Coordenação do Subprojeto Inova.Jab conseguiram implantar um organismo que demonstra ter muito a contribuir socialmente e economicamente.

A análise da gestão da incubadora mostra acertos na estruturação física da incubadora e na grande quantidade de networking com o mercado, professores e laboratórios, corroborando para a afirmação de que a Inova.Jab foi muito bem estruturada. Por outro lado, alguns pontos a serem revistos e melhores estruturados referem-se ao processo de seleção, especificidades dos cargos, normas claras para a graduação e proposição dos processos e práticas da gestão.

Os objetivos propostos no trabalho foram completamente atendidos na pesquisa. Como as atividades da Inova.Jab encontram-se no início, não foi possível realizar uma análise ainda mais ampla a respeito, principalmente, da sobrevivência das empresas que passam pelo processo de incubação, do relacionamento contínuo e monitoramento das empresas incubadas, da atuação da Equipe Executora para a graduação das empresas e da avaliação organizacional através de indicadores de desempenho.

Espera-se que este trabalho possa contribuir para o crescimento da Inova.Jab e também auxilie a implantação ou análise da gestão por outras incubadoras. Ainda, um estudo que acrescente 


\section{também a participação das empresas incubadas pela Inova.Jab para avaliar a gestão da incubadora é indicado como possibilidade de pesquisa futura.}

\section{REFERÊNCIAS}

ALON, I.; GODINHO, M. M. Business Incubators in a Developing economy: Evidence from Brazil's Northeast Region. Science and Public Policy, p. 1-13, abr.2016.

ANPROTEC. Estudo de Impacto Econômico: Segmento de Incubadoras de Empresas do Brasil. Brasília: ANPROTEC: SEBRAE, 2016. 26 p.

ANPROTEC. Incubadoras e Parques. Associação Nacional de Entidades Promotoras de Empreendimentos Inovadores, 2017. Disponivel em: <http://anprotec.org.br/site/menu/incubadoras-e-parques/perguntas-frequentes/>. Acesso em: 10 Setembro 2017.

ANPROTEC. CERNE, 2018. Disponivel em: <http://anprotec.org.br/cerne/> Acessado em: 20 outubro 2018.

ANPROTEC, A. N. D. E. P. D. E. I.-. Cerne - Centro de Referência para Apoio a Novos Empreendimentos, Brasília, v. 3, n. 3, 2014.

AZIH, E.; INANGA, E. L. Performance Effectiveness of Technology Incubation in Nigeria. Business and Economics Journal, v. 5, n. 4, jul/nov. 2014.

BARBOSA, L. G. D. F.; HOFFMANN, V. E. Incubadora de empresas de base tecnológica: percepção dos empresários quanto aos apoios recebidos. Revista de Administração e Inovação, São Paulo, v. 10, n. 3, p. 208-229, jul./set. 2013.

CAMARGO, B. V.; JUSTO, A. M. Tutorial para uso do Iramuteq (Interface de R pour les analyses multidimensionnelles de textes et de questionnaires). Laboratório de Psicologia Social da Comunicação e Cognição. Universidade Federal de Santa Catarina, p. 74, 2018. Disponivel em: <http://www.iramuteq.org/documentation/fichiers/tutoriel-portugais-22-11-2018> Acessado em: novembro 2018.

COSTA, L. F. S. D.; FRANÇA, M. C. L.; TEIXIERA, R. M. Apoio gerencial na incubação de empresas de base tecnológica: o caso da incubadora CISE. Revista Pensamento Contemporâneo em Administração, Rio de Janeiro, v. 4, p. 1-15, jan./abr. 2010.

DAL-SOTO, F.; SUZIN, J. B. Práticas da análise de conteúdo no campo de gestão estratégica. Revista de Administração da Unimep, v. 15, n. 4, set./dez 2017.

DEE, N., GILL, D. E., LIVESEY, T. F., MINSHALL, T. H. W. Incubation for Growth: A Review of the Impact of Business Incubation on New Ventures with High Growth Potential. NESTA. [S.1.]. 2011. disponível em: <https://media.nesta.org.uk/documents/incubation_for_growth. pdf> Acessado em: novembro 2018.

DONADON, F. A. B. Estratégias de inovação e modelos de negócio da agroindústria brasileira: um estudo multicasos. Jaboticabal. 2018. 174 f. Dissertação (mestrado em administração) Universidade Estadual Paulista. 
DVOUlETÝ, O., LONGO, M. C., BLAŽKOVÁ, I., LUKEŠ, M., ANDERA, M. Are publicly funded Czech incubators effective? The comparison of performance of supported and nonsupported firms. European Journal of Innovation Management, v. 21, n. 4, p. 543-563, out. 2018.

ENGELMAN, R.; FRACASSO, E. M. Contribuição das Incubadoras Tecnológicas na Internacionalização das Empresas Incubadas. Revista de Administração, São Paulo, v. 48, n. 1, p. 165-178, mar. 2013.

ETZKOWITZ, H. The triple helix: science, technology and the entrepreneurial spirit. Journal of knowledge-based Innovation in China, v. 3, p. 76-90, jul. 2011.

ETZKOWITZ, H.; KLOFSTEN, M. The innovation region: toward a theory of knowledge-based regional development. $R \mathcal{E} D$ Management, v. 3, jun. 2005.

ETZKOWITZ, H.; LEYDESDORFF, L. The Dynamics of Innovation: from National Systems and "Mode 2" to a Triple Helix of University-Industry-Government Relations. Research Policy, v. 29, p. 109-123, fev. 2000.

FAPESP. Fundação de Amparo à Pesquisado Estado de São Paulo. Relatório atividades fapesp 2017. Disponível em: <http://www.fapesp.br/relatorios_2017/RA2017.pdf> Acessado em: setembro 2018.

FCAV. Sobre a FCAV. Faculdade de Ciências Agrárias e Veterinárias, 2018. Disponivel em: $<$ http://www.fcav.unesp.br/\#!/sobre-a-fcav/>. Acessado em setembro 2018.

FERREIRA, C. A. L. Pesquisa Quantitativa e Qualitativa: perspectivas para o campo da educação. Revista Mosaico, v. 8, n. 2, p. 173-182, dez. 2015.

FERREIRA, M. P., DE ABREU, A. F., DE ABREU, P. F., TRZECIAK, D. S., APOLINÁRIO, L. G., DA CUNHA, A. D. A. Gestão por indicadores de desempenho: resultados na incubadora empresarial tecnológica. Produção, v. 18, n. 2, p. 302-318, maio/ago. 2008.

FONSECA, S. A.; JABBOUR, C. J. C. Assessment of business incubator's green performance: a framework and its application to Brazilian cases. Technovation, v. 32, p. 122-132, fev. 2012.

GARCIA, F. P.; BIZZOTTO, C. E.; PIRES, S. O.; CHIERIGHINI. T. Reference Center for Business Incubation: a proposal for a new model of operation. ANPROTEC. [S.1.], p. 12. 2015. Disponível em: http://www.anprotec.org.br/Relata/artigoCernNBIA.pdf . acessado em: dezembro 2018.

GODOY, A. S. Pesquisa qualitativa: tipos fundamentais. Revista de Admnistração de empresas, São Paulo, v. 35, n. 3, p. 20-29, mai/jun. 1995.

INFODEV. Business Incubation Definition and Principles. [S.1.]: [s.n.], 2009. Disponivel em: $<$ https://www.infodev.org/infodev-files/m1_traineemanual_20101029.pdf >. Acessado em: novembro 2018.

INOVA.JAB. Inova.Jab, 2018. Disponivel em: <http://www.inovajab.com.br/>.Acessado em setembro 2017.

KAPLAN, R. S.; NORTON, D. P. The balanced scorecard: Measures that drive performance. Harvard Business Review, p. 71-79, Jan/Fev. 1992. 
KORONTAI, J. N., CARPEJANI, G., CORREIA, A. M. M., de FREITAS, W. A., da VEIGA, C. P., DUCLÓS, L. C. Proposta de indicadores de desempenho para a incubadora tecnológica do Instituto de Tecnologia do Paraná / Brasil. Espacios, v. 37, n. 2, p. 20, set/out. 2016.

LIMA, S. M., DE MACÊDO, J. L., DE AQUINO CABRAL, A. C., COLARES, R. F. Estrutura Organizacional das Empresas Vinculadas à Incubadora de Base Tecnológica da Universidade de Fortaleza: Uma Análise Sob a Perspectiva de Mintzberg. Revista de Gestão, São Paulo, v. 21, n. 3, p. 305-324, jul./set. 2014.

MACHADO, A. D. B.; SILVA, A. R. L. D.; BIZZOTTO, C. E. N. Mapping of Management Model For Business Incubator. Journal of Business and Management, v. 19, n. 5, p. 28-34, Maio. 2017.

MANSANO, F. H.; PEREIRA, M. F. Business Incubators as Support Mechanisms for the Economic Development: Case of Maringá's Technology Incubator. International Journal of Innovation, São Paulo, v. 4, n. 1, p. 23-32, Jan./Jun. 2016.

MANTOVANI, D. M. N., GRANITO, R. A. N., CABRAL, D. G., LEITE, M. F. B. O Papel das Incubadoras de Empresas no Desenvolvimento Local: Um Estudo de Caso. Revista de Administração e Inovação, São Paulo, v. 3, n. 1, p. 90-101, 2006.

MANZINI, E. J. Entrevista semi-estruturada: análise de objetivos e de roteiros. Seminário Internacional Sobre Pesquisa e Estudos Qualitativos, Bauru, v. 1, p. 01-10, 2004.

MARCONI, M. D. A.; LAKATOS, E. M. Fundamentos de metodologia científica. 5. ed. São Paulo: Atlas, 2003.

MARTELO, M. R.; CLARO, J. A. C. S.; VIEIRA, A. M. Clima Organizacional no contexto de uma incubadora: estudo com três Empreendimentos do interior de São Paulo. Revista FSA, v. 13, p. 24-49, 2016.

M'CHIRGUI, Z. Assessing the Performance of Business Incubators: Recent France Evidence. Business and Management Research, v. 1, n. 1, p. 62-76, Mar. 2012.

MIAN, S.; LAMINE, W.; FAYOLLE, A. Technology Business Incubation: An Overview of the State of Knowledge. Technovation, v. 50, p. 1-12. abr/maio. 2016.

MINISTÉRIO DE CIÊNCIA, T. E. I.-. Parques \& Incubadoras para o Desenvolvimento do Brasil: Estudos de Impactos do PNI: Programa Nacional de Apoio a Parques Tecnológicos e Incubadoras de Empresas. Brasília, p. 191. 2015.

MÜlLER, A. C. M., LUCION, E. V., PRESRLAK, M. I., ROJO, C. A. Proposta de indicadores de evolução de empresas incubadas: gestão baseada na metodologia CERNE. Gestão \& Tecnologia, Pedro Leopoldo, v. 17, n. 3, p. 264-283, Set./Dez. 2017.

ORTIGARA, A. A., GRAPEGGIA, M., JULiATTO, D. L., LEZANA, Á. G. R., BASTOS, R. C. Análise por agrupamento de fatores de desempenhos das incubadoras de empresas. Revista de Administração e Inovação, São Paulo, v. 8, n. 1, p. 64-91, jan./mar 2011.

ROSA, L. ITSM: Um Caso de Sucesso do Modelo Tríplice Hélice. Revista de Administração da UFSM, Santa Maria, v. 7, n. Edição Especial, p. 55-69, Set. 2014.

RUBIN, T. H.; AAS, T. H.; STEAD, A. Knowledge Flow in Technological Incubators: Evidence from Australia and Israel. Technovation, v. 41, p. 11-24, mar. 2015. 
SANTOS, P. M.; MORAES FILHO, R. A. D. Empreendedorismo na Incubadora da UFRPE: Uma Reflexão sobre Empresas Criadas por Iniciativas de Alunos e Docentes. Organizações em Contexto, São Bernardo do Campo, v. 10, n. 20, p. 371-406, jul/dez. 2014.

SANTOS, M. M. O.; QUEL, L. F.; VIEIRA, A. M.; ROSINI, A. M. Indicadores de Desempenho e Engajamento Profissional em Organizações Inovadoras. Revista de Gestão e Secretariado, v. 10, n. 1, p. 192-212, 2019.

SEBRAE. Quais os Tipos de Incubadoras Existentes. Serviço de Apoio às Micro e Pequenas Empresas de Santa Catarina, 2017. Disponivel em: <http://www.sebrae-sc.com.br/leis/default. asp?vcdtexto=4827\&\%5E\%5E >. Acesso em: 24 Setembro 2017.

SOUZA, L. A., DANTAS, P. F., EL AOUAR, W. A., BARRETO, L. K. S. Modelo de Gestão em incubadoras e mapas de desempenho. Revista Ciências Administrativas, Fortaleza, v. 21, n. 1, p. 112-130, jan/jun 2015.

STOROPOLI, J. E.; BINDER, M. P.; MACCARI, E. A. Incubadora de Empresas e o Desenvolvimento de Capacidades em Empresas Incubadas. Revista de Ciências da Administração, v. 15, n. 35, p. 36-51, Abr. 2013.

TISOTT, P. B., NESPOLO, D., DE ÁVILA DIAS, D. T., OLEA, P. M., MILAN, G. S. Incubadora Tecnológica de Caxias do Sul: inovação tecnológica sob a perspectiva da hélice tríplice. Administração: Ensino e Pesquisa, Rio de Janeiro, v. 15, n. 3, p. 561-591, Jul./Set 2014.

VANDERSTRAETEN, J.; WITTELOOSTUIJN, A. V.; MATTHYSSENS, P. Measuring the performance of business incubators. University of Antwerp, Faculty of Business and Economics, jun. 2012.

VIEIRA, A. M.; RIVERA, D. P. B. A Hermenêutica no Campo Organizacional: duas possibilidades interpretativistas de pesquisa. Revista Brasileira de Gestão de Negócios, v. 14, n. 44, p. 261-273, 2012.

XAVIER, W. S.; MARTINS, G. S.; LIMA, A. A. T. D. F. D. C. Capacitação Gerencial nas Incubadoras de Base Tecnológica: Proposição de um Modelo Matricial de Avaliação. Revista de Ciências da Administração, v. 13, n. 29, p. 88-111, jan/abr 2011.

XIAO, L.; NORTH, D. The Graduation Performance of Technology Business Incubators in China's Three Tier Cities: the role of incubator funding, technical support, and entrepreneurial mentoring. The Journal of Technology Transfer, v. 42, p. 615-634, 2017.

XU, L. Business Incubation in China: effectiveness and perceived contributions to tenant enterprises. Management Research Review, v. 33, n. 1, p. 90-99, 2010. 


\section{APÊNDICE A}

Roteiro da entrevista semiestruturada

Dados de identificação do entrevistado
1. Cargo
2. Vínculo
3. Gênero
4. Data de ingresso
5. Tempo

Perguntas da entrevista

1. Qual o número de empresas em processo de incubação atualmente?

2. Qual o número de empresas graduadas?

3. Alguma empresa já abandonou o processo de incubação? Quais os motivos?

4. Quantos empregos foram criados pelas empresas incubadas?

5. Qual o perfil de negócio das empresas incubadas?

6. Há a constatação de algum produto, serviço ou processo inovador já lançado ao mercado por alguma empresa incubada ou graduada pela InovaJab? Se positivo, você poderia descrever a empresa/segmento de atuação e o produto?

7. Quais ações são desempenhadas pela FCAV para estimular o empreendedorismo? Quais ações, características ou condições atualmente existentes na FCAV limitam o empreendedorismo?

8. A InovaJab oferece consultorias, assessorias e treinamentos específicos às necessidades de cada empresa? Fale um pouco a respeito.

9. As empresas incubadas podem utilizar os espaços de pesquisa e laboratórios da FCAV? Se positivo, como essa interação pode ocorrer? Além disso, as empresas têm relacionamento com os professores e pesquisadores da FCAV?

10. As empresas participam de rodadas de negócios, eventos e feiras?

11. As empresas têm acesso a recursos financeiros/financiamentos por meio do auxílio da incubadora? 
12. A InovaJab estimula a interação e integração das empresas incubadas com pessoas de maior experiência de mercado? Se sim, como?

13. Quais os serviços e recursos oferecidos pela InovaJab para as empresas incubadas? Fale um pouco a respeito.

14. A InovaJab tem relacionamento contínuo e/ou realiza o monitoramento das empresas? Como são realizados os processos?

15. A InovaJab hospeda empresas já estabilizadas, associações, sindicatos e instituições públicas?

16. A InovaJab apresenta políticas e normas claras de seleção e graduação das empresas?

17. A InovaJab tem alguma parceria com o poder público municipal local? E com os governos Estadual e Federal?

18. A InovaJab tem alguma parceria com o setor privado?

19. A equipe gestora da InovaJab tem profissionalização específica na área que atua?

20. A InovaJab avalia e monitora a disponibilização de fundos públicos direcionados às incubadoras e as empresas incubadas?

21. A InovaJab segue algum modelo de gestão para incubadoras de empresas? Fale um pouco a respeito.

22. A InovaJab tem conhecimento do modelo de gestão Cerne proposto pela Anprotec?

23. A InovaJab realiza a avaliação de desempenho organizacional? Fale um pouco a respeito. 